\title{
Psychophysiological Effectiveness of Calmvalera Hevert Tablets as Measured by EnkephaloVision in Anxious Subjects during Audio-Visual Cognitive and Emotional Challenges: A Double-Blind, Randomized, Placebo-Controlled, 2-Armed, Phase IV Study in Parallel Design
}

\author{
Wilfried Dimpfel1, Sieglinde Tausend², Samir Suliman³, Gwladys N. Chiegoua Dipah³ \\ ${ }^{1}$ Justus-Liebig-University, Giessen, Germany \\ ${ }^{2}$ Hevert-Arzneimittel GmbH \& Co. KG, Nussbaum, Germany \\ ${ }^{3}$ NeuroCode AG, Wetzlar, Germany \\ Email: dimpfel1945@web.de
}

How to cite this paper: Dimpfel, W., Tausend, S., Suliman, S. and Dipah, G.N.C. (2016) Psychophysiological Effectiveness of Calmvalera Hevert Tablets as Measured by EnkephaloVision in Anxious Subjects during Audio-Visual Cognitive and Emotional Challenges: A Double-Blind, Randomized, Placebo-Controlled, 2-Armed, Phase IV Study in Parallel Design. Journal of Behavioral and Brain Science, 6, 404-431.

http://dx.doi.org/10.4236/jbbs.2016.610039

Received: August 25, 2016

Accepted: September 27, 2016

Published: September 30, 2016

Copyright $\odot 2016$ by authors and Scientific Research Publishing Inc. This work is licensed under the Creative Commons Attribution International License (CC BY 4.0).

http://creativecommons.org/licenses/by/4.0/

(c) (i) Open Access

\begin{abstract}
Subjects suffering from anxiety during examinations often take drugs with considerable side effects. As alternative, homeopathic preparations virtually lack side effects in general. However, clinical efficacy has to be demonstrated. This experimental series was initiated to provide evidence, that Calmvalera Hevert tablets, marketed for treatment of nervous restlessness and better coping with stress, have an influence on brain electric activity. In order to test this, a new clinical design was used: "EnkephaloVision". It consists of the combination of quantitative EEG recording with time epochs of $364 \mathrm{~ms}$ (Neurocode-Tracking) with conventional Eye-Tracking. Seventeen channels of EEG and one channel EOG were recorded. After frequency analysis (FFT) current source density was calculated. Recording was performed in the presence of a video clip, which contained several different cognitive and emotional challenges in series. Twenty-four male and female subjects having a score $>60$ in an anxiety questionnaire (Prüfungsangstfragebogen PAF-S) were recruited to participate. A correlation between the Hamilton anxiety score and spectral alphal power during the recording condition "eyes open" before drug intake was detected. Spectral power was averaged including $\mathrm{C}_{z}, \mathrm{~F}_{3}$ and $\mathrm{F}_{4}$ electrode positions. Audiovisual challenges induced spectral changes with respect to delta, theta and beta power, not in the alpha ranges, to a different but statistically significant degree. Intake of Calmvalera Hevert
\end{abstract}


tablets resulted in statistically significant increases of alpha1 and alpha2 spectral power during most of the recording conditions within the left hemisphere. Increases of alpha activity have been related to relaxation and calmness as reported in the literature. Discriminant analysis of the whole data set revealed a clear difference between verum and placebo and a projection of the data into the vicinity of other plantderived calming preparations. Performance of psychometric tasks was not disturbed. Efficacy of Calmvalera Hevert tablets points to active molecules contained due to low triturations (D2 - D8).

\section{Keywords}

EEG Source Density, Spectral Power, Calmvalera Hevert Tablets, Cognition, Psychophysiology, CATEEM ${ }^{\circledast}$, Neurocode-Tracking, Eye-Tracking,

EnkephaloVision

\section{Introduction}

Anxiety during examinations and similar conditions is a widespread phenomenon that very often leads to intake of drugs with considerable side effects. An alternative therapy might consist in using complex homeopathic medicines with a better tolerability. Among these, one preparation is based on nine mainly plant derived homeopathic triturations (potencies D2 to D8) and is marketed in Germany under the name of Calmvalera Hevert tablets for the treatment of nervous restlessness and sleep disorders including better coping with stress.

Many other preparations from herbal origin have been tested using neurophysiological techniques [1]-[4]. The present investigation aimed at the possibility, that Calmvalera Hevert tablets might be able to help subjects suffering from examination anxiety. In order to test this, a new design of a clinical study was used, namely "EnkephaloVision". This new approach consists of the combination of quantitative EEG recording providing very high time resolution of epochs of $364 \mathrm{~ms}$ (Neurocode-Tracking) with conventional Eye-Tracking [5].

There is convincing evidence that emotional states directly relate to brain electric activity in terms of spectral frequency changes [6]. Also, according to our experience, when presenting videos with emotional content, reproducible changes of brain electric activity have been recorded [7]. In the present study, twenty-four subjects suffering from examination (or test) anxiety were exposed audio-visually to 5 cognitive and 5 emotional challenges by asking for task performance and watching video clips of short durations. It was hoped that the drug would induce specific changes of electric features related to a calming action.

\section{Methods}

\subsection{Subjects}

Twenty-four healthy male and female subjects aged 18 - 40 years were recruited by ad- 
vertisements in newspapers. Using an anxiety questionnaire (Prüfungsangstfragebogen PAF-S from Hogrefe Verlag, Göttingen, Germany [8]) only subjects having score values above 60 were selected to participate in the study. Score value 60 is the cut off for being healthy according to evaluation criteria of the test. Subjects must have been capable of giving informed consent. Subjects had to meet following exclusion criteria:

- Acute or chronic disease with an impact on the study, which becomes obvious by case history or clinical examination (i.e. also Hamilton depression scale).

- Clinically relevant pathological findings from clinical and laboratory findings.

- Clinically relevant allergic symptoms.

- Detection of alcohol at the time of initial examination (screening day SC) or on study day A (positive alcohol test) or by case history. Detection of drugs (positive drug test) at the time of initial examination (screening day SC).

- Consumption of clinically relevant medication during last fourteen days before and during the active study period based on the notification of the subject or his case history.

- Consumption of medication with primarily central action (i.e. psychotropic drugs or centrally acting antihypertensives). Known intolerance/hypersensitivity (allergy) to plant derived extracts (Cimicifuga, Cocculos, Passiflora, Valeriana etc.) or any of the ingredients of the investigational product (anamnestic). Presence of a rare genetic disease such as fructose intolerance, glucose-galactose malabsorption or sucrase-isomaltase deficiency (anamnestic).

- BMI (Body Mass Index) $<18$ or $>32$.

- Consumption of unusual quantities or misuse of coffee (more than 4 cups a day), tea (more than 4 cups a day) or tobacco (more than 20 cigarettes per day).

- Smoking on study day A.

- Participation in another clinical trial within the last 60 days.

- Positive pregnancy test (study day A).

- Lactation.

- Cancellation of informed consent.

\subsection{Trial Medication}

Ingredients of Calmvalera Hevert tablets and placebo tablets are listed in Table 1 and Table 2.

Each subject was asked for intake of 6 tablets (daily dosage) at a time. The subjects selected for the study had a normal physical examination, electrocardiogram (ECG) and blood count for safety reasons. Laboratory tests for safety are listed in Table 3. Average age of the subjects was $24.88 \pm 4.21$ years.

\subsection{Quantitative EEG}

EnkephaloVision is the term for the entirely new combination of quantitative EEG (Neurocode-Tracking) and Eye-Tracking.

In this study a 17-channel EEG recording was combined with Eye-Tracking. Details 
Table 1. Calmvalera hevert-tablets (registration No. 77957.00.00-product insert: November 2014).

\begin{tabular}{ccc}
\hline & Composition & \\
\hline 1 tablet contains active ingredients: & & \\
Cimicifuga & Trit. D3 & $20 \mathrm{mg}$ \\
Cocculus & Trit. D4 & $20 \mathrm{mg}$ \\
Cypripedium pubescens & Trit. D4 & $10 \mathrm{mg}$ \\
Ignatia & Trit. D6 & $40 \mathrm{mg}$ \\
Lilium tigrinum & Trit. D6 & $20 \mathrm{mg}$ \\
Passiflora incarnata & Trit. D3 & $40 \mathrm{mg}$ \\
Platinum metallicum & Trit. D8 & $20 \mathrm{mg}$ \\
Valeriana & Trit. D2 & $20 \mathrm{mg}$ \\
Zincum valerianicum & Trit. D3 & $20 \mathrm{mg}$ \\
\hline
\end{tabular}

Other ingredients: lactose-monohydrate (35 mg), magnesium stearate (Ph. Eur.), corn starch.

Table 2. Content of placebo tablets.

\begin{tabular}{lc}
\hline \multicolumn{2}{c}{ Composition } \\
\hline Lactose/62\% Ethanol Trit. & $105,00 \mathrm{mg}$ \\
Lactose/43\% Ethanol Trit. & $110,00 \mathrm{mg}$ \\
Lactose/Lactose Trit. D3 & $2000 \mathrm{mg}$ \\
Lactose/Glycerin/Ethanol 43\% Trit. & $1000 \mathrm{mg}$ \\
Other ingredients: & \\
Corn starch & $750 \mathrm{mg}$ \\
Magnesium stearate & $100 \mathrm{mg}$ \\
Final product doesn't contain anymore Excipient (s): & $3500 \mathrm{mg}$ \\
Purified water & $500 \mathrm{mg}$ \\
Ethanol 96\% (V/V)
\end{tabular}

Table 3. Schedule of examinations and procedures.

\begin{tabular}{cccc}
\hline Laboratory Tests for safety & Screening day SC & Study day A & $\begin{array}{c}\text { Final Examination } \\
\text { day FE }\end{array}$ \\
\hline $\begin{array}{c}\text { Clinical Examination } \\
\text { Vital Signs (pulse rate, temperature, } \\
\text { respiration rate, and blood pressure) }\end{array}$ & $\mathrm{x}$ & $\mathrm{x}$ & $\mathrm{x}$ \\
ECG for safety & $\mathrm{x}$ & $\mathrm{x}$ & $\mathrm{x}$ \\
Alcohol Test & $\mathrm{x}$ & $\mathrm{x}$ \\
$\begin{array}{c}\text { Drug-Test (MAHSHAN-KOMBI/ } \\
\text { DOA 10 quick test) }\end{array}$ & $\mathrm{x}$ & $\mathrm{x}$ & \\
$\begin{array}{c}\text { Pregnancy Test for female } \\
\text { (BioSign-HCG-quick test) }\end{array}$ & & & \\
Laboratory Tests for safety & & $\mathrm{x}$ \\
$\left(\right.$ Na ${ }^{+}$, GOT, GPT, GGT, Kreatinin, & $\mathrm{x}$ & & \\
Glucose in serum, blood count) & & $\mathrm{x}$ \\
Urine (Status, Sediment) & & & \\
\hline
\end{tabular}


of the EEG recording have been published earlier [4] but a new modified software for analysis of shorter time epochs of $364 \mathrm{~ms}$ duration was used (neo-CATEEM ${ }^{\oplus}$, supplied by MEWICON CATEEM-Tec GmbH, 4164 Schwarzenberg am Böhmerwald, Austria). A manuscript containing details and validation of the software package-now called "Neurocode-Tracking"-has been published [5]. In short: For the new approach EEG frequency ranges to be analyzed had to be adjusted slightly to give the following exact ranges. Delta: 1.375 - $4.125 \mathrm{~Hz}$; Theta: 4.125 - $6.875 \mathrm{~Hz}$; Alpha1: 6.875 - 9.625 Hz; Alpha2: 9.625 - 12.375 Hz; Beta1: 12.375 - 17.875 Hz; Beta2: 17.875 - 34.375 Hz. This adjustment is a precondition for the new fast dynamic frequency analysis (NeurocodeTracking) because under this condition each frequency range from delta up to alpha2 contains only one frequency (middle frequency within the particular frequency band). Data were analyzed in the current source density mode. All other features remained identical to the classic analysis used now for nearly 20 years. Maps were constructed by transforming spectral power values into spectral colors followed by additive color mixture (RGB-mode like in TV).

EEG recording was performed in the presence of a video clip, which contained several different cognitive and emotional challenges in series. At the beginning, after a gong for synchronization purposes, one minute was recorded under relaxation (eyes open) as reference, followed by presentation of a fixation cross. After this several cognitive and emotional challenges were presented: The total video was presented before and after intake of 6 tablets with some changes of cognitive tasks for prevention of memorized results. Between baseline recording and intake of Calmvalera Hevert or placebo tablets subjects had a pause for 90 minutes in the restroom. The time line of consecutive scenes is documented in the following Table 4.

Table 4. Time line of consecutive presentations.

\begin{tabular}{|c|c|c|}
\hline \multicolumn{3}{|c|}{ EnkephaloVision Neurocode-Tracking in Combination with Eye-Tracking Audio-visual Presentations } \\
\hline & Elements & Time \\
\hline 1 & Instructions of volunteers in the Neurocode-Tracking method & $5 \mathrm{~min} .00 \mathrm{~s}$ \\
\hline 2 & Gong (for synchronization Neurocode-Tracking (qEEG and Eye-Tracking)) & $21 \mathrm{~s}$ \\
\hline 3 & Black screen (Eyes open) & $1 \mathrm{~min} .00 \mathrm{~s}$ \\
\hline 4 & Fix Cross (Eyes open) & $1 \mathrm{~min} .00 \mathrm{~s}$ \\
\hline 5 & Picture Comparison ( $\mathrm{n}=1$ foil) with 8 errors including instructions & $1 \mathrm{~min} .15 \mathrm{~s}$ \\
\hline 6 & Stroop-Test $(\mathrm{n}=1$ foil) including instructions & $1 \mathrm{~min} .00 \mathrm{~s}$ \\
\hline 7 & Memory-Test $(\mathrm{n}=4$ tasks) including instructions & $1 \mathrm{~min} .35 \mathrm{~s}$ \\
\hline 8 & CPT-Test (concentration performance test) ( $\mathrm{n}=4$ tasks) including instructions & $2 \mathrm{~min} .20 \mathrm{~s}$ \\
\hline 9 & Brain Teaser $(\mathrm{n}=10$ foils) including instructions & $5 \min .15 \mathrm{~s}$ \\
\hline 10 & Emotional Pictures & $1 \mathrm{~min} .19 \mathrm{~s}$ \\
\hline & Video "Exam Anxiety" & $1 \mathrm{~min} .55 \mathrm{~s}$ \\
\hline 12 & Video "Dentist Pain" & $52 \mathrm{~s}$ \\
\hline 13 & Video “Emergency-OP” (Horror-OP) & $52 \mathrm{~s}$ \\
\hline 14 & Video "Horror" & $1 \mathrm{~min} .33 \mathrm{~s}$ \\
\hline & Total Time & $20 \mathrm{~min} .17 \mathrm{~s}$ \\
\hline
\end{tabular}




\subsection{Eye-Tracking}

Eye-Tracking (equipment and software from Tobii Technology GmbH, Frankfurt, Germany), was performed concomitantly with Neurocode-Tracking (fast dynamic quantitative EEG recording). All mental and emotional challenges were presented as a single video clip. Single challenges were first constructed as a power point file and then converted into a final video clip (by Adobe Captivate software). For offline analysis and synchronization with the eye-track data a screen grabber (Adobe Captivate software) was used to produce a video containing all successively calculated EEG maps of $364 \mathrm{~ms}$ duration. A second video was obtained from the eye-tracker software running on a separate computer. It is called a "gaze overlay" movie depicting the presented pictures, tasks or video film. In this gaze overlay video the momentary gaze of the subject is documented by a red spot. Data from the whole group are depicted as so-called heat maps. The presentation always started with an audio signal (gong). This audio signal was registered by screen capture of the EEG computer and was used for synchronization of both videos by means of a video cut software (Adobe Premiere Pro). Due to the processing time of the brain (300 to $400 \mathrm{~ms}$ ) plus that of the computer (depends individually on the type and number of active processors!) the gaze overlay video is shifted in our case (quad core, 3.4 Giga-Hz) for one second in order to obtain synchronized images between gaze and the particular EEG epoch of $364 \mathrm{~ms}$. For detailed offline documentation a movie was exported and analyzed image by image. Single representative images containing the gaze and corresponding EEG map were cut from the screen by a software tool available on all computers.

\subsection{Experimental Design}

On the experimental day (Day A), subjects started with a standardized breakfast. After this two questionnaires had to be filled out: Hamilton depression scale (HAMD) [9] and Hamilton anxiety scale (HAMA) [10] before randomization took place. Then, Enkephalo Vision session was started. A time line is given in Figure 1.

\subsection{Statistics}

EEG data from the first recording session before intake of the capsules are given as ab-

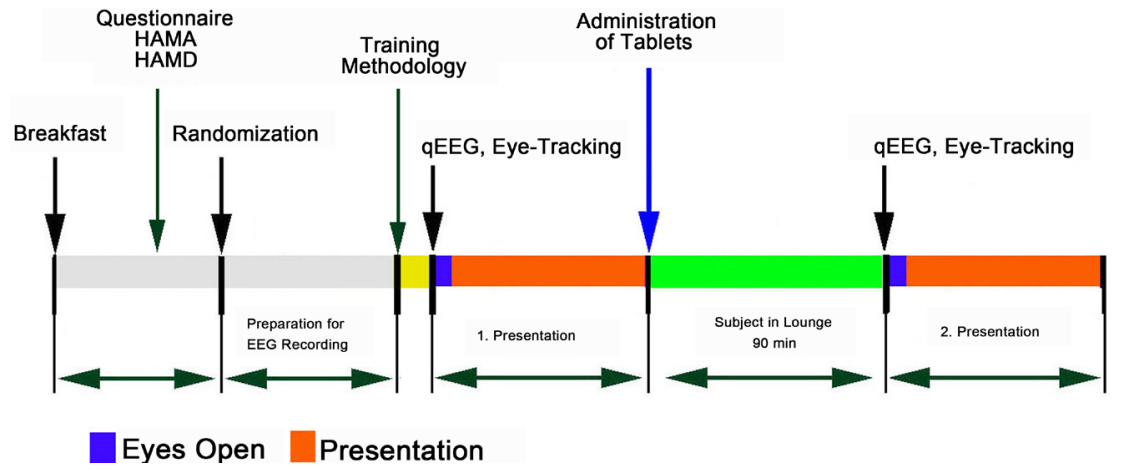

Figure 1. Time line of procedures on experimental day (Day A). Subject in lounge: 90 minutes. 
solute numbers $\left(\mu \mathrm{V}^{2}\right)$. For explorative statistical evaluation the nonparametric Wilcoxon test was used. For mathematical differentiation of the different mental loads the linear discriminant analysis according to Fischer was used. Results from the first three discriminant functions were projected into space (X, Y and Z coordinates), whereas results from the fourth to sixth discriminant functions were coded into red, green and blue color, respectively, followed by an additive color mixture (so-called RGB-mode). In order to document statistically the different electric reaction of the brain to various cognitive and emotional loads, data from each part of the presentation were divided by the data obtained during recording of a relaxed state with eyes open ( 1 minute) at the beginning. Comparison of Calmvalera Hevert tablets versus placebo was accomplished by evaluation of the second recording of the day 90 minutes after intake. Data from the first recording (baseline) were set to $100 \%$ and electrophysiological changes produced by placebo or Calmvalera Hevert tablets are depicted as \%-changes thereof. Sample size was defined according to several earlier studies performed under identical conditions.

\subsection{Ethics and Authority Approval}

The study was conducted according to the protocol after approval by the BfArM (Bonn, Germany) and Ethikkommission (Landesärztekammer Frankfurt, Germany) (PP_5014 _HEVERT_FINAL V1.0_23042015) and “Amendment 1 for PP_5014_HEVERT_FIN AL V1.0_23042015”.

\section{Quantitative EEG and Hamilton Anxiety Questionnaire}

\subsection{Basic Considerations}

Twenty-four subjects were recruited for this study on the base of filling out a questionnaire dealing with examination anxiety. Concomitant presentation of a series of mental and emotional challenges during recording of the EEG was performed before and 90 minutes after intake of 6 Calmvalera Hevert tablets or placebo. The absolute starting values of spectral power in the six frequency ranges (delta to beta2) are given in Table 5. These values do not differ from each other in a statistically significant way suggesting that both groups placebo and verum have a similar starting position. This allows for a pre-post comparison of drug action. These absolute values are set to $100 \%$ and drug induced changes are documented in \% of these starting values.

In order to relate the result from the anxiety questionnaire "HAMA" with EEG parameters a correlation was searched based on the first recordings before administration of the drug. The result indicates that absolute spectral alpha power from all 24 subjects during the recording condition "eyes open" in a relaxed state before drug administration correlated with the score values of the questionnaire. Figure 2 and Figure 3 document the results of this analysis showing a correlation coefficient $r=-0.418(\mathrm{p}<0.017)$ for alphal and $\mathrm{r}=-0.329(\mathrm{p}<0.084)$ for alpha 2 spectral power.

\subsection{Spectral Frequency Changes during Audio-Visual Challenges}

Next step in the analysis was to find out if the different cognitive and visually presented 


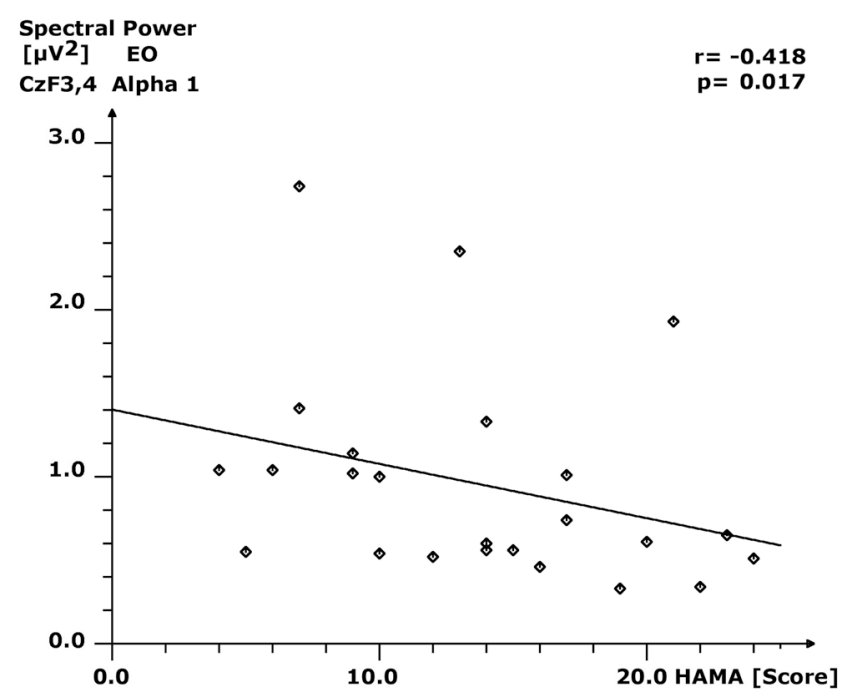

Figure 2. Correlation between HAMA anxiety questionnaire (score on abscissa) and spectral alphal power during the recording condition "eyes open" before drug intake. Spectral power was averaged including $\mathrm{C}_{\mathrm{z}}, \mathrm{F}_{3}$ and $\mathrm{F}_{4}$ electrode positions. Correlation coefficient $(\mathrm{r}=-0.418 ; \mathrm{p}=$ 0.017).

Table 5. Spectral power before intake of placebo/verum ( $\mathrm{Pl} / \mathrm{Ve})$ with respect to 17 locations under the recording condition "eyes open" before acute intake at day A. Comparison of the absolute starting values of both groups of subjects. Data are given as $\mu \mathrm{V}^{2}$ within each frequency range (delta-beta2). Med = median value. Electrode positions according to the so-called 10/20 system [11]. Pl = placebo; $\mathrm{Ve}=$ Calmvalera Hevert tablets.

\begin{tabular}{cccccc}
\hline \multicolumn{5}{c}{ Absolute Spectral Power during relaxation (eyes open) $0 \mathrm{~h}$ before acute intake at day A } \\
\hline Delta & Theta & Alpha 1 & Alpha 2 & Beta 1 & Beta 2
\end{tabular}

Subjects $\mathrm{n}=12 \mathrm{n}=12 \quad \mathrm{n}=12 \quad \mathrm{n}=12 \quad \mathrm{n}=12 \quad \mathrm{n}=12 \quad \mathrm{n}=12 \quad \mathrm{n}=12 \quad \mathrm{n}=12 \quad \mathrm{n}=12 \quad \mathrm{n}=12 \quad \mathrm{n}=12$

Electrode Placebo Verum Placebo Verum Placebo Verum Placebo Verum Placebo Verum Placebo Verum

\begin{tabular}{ccccccccccccc}
$\mathrm{Cz}$ & 1.21 & 1.21 & 0.77 & 0.85 & 0.34 & 0.62 & 0.51 & 0.47 & 0.38 & 0.42 & 0.57 & 0.59 \\
$\mathrm{Fz}$ & 2.12 & 2.55 & 1.30 & 1.70 & 0.77 & 1.17 & 1.13 & 0.71 & 0.62 & 0.61 & 0.75 & 0.84 \\
$\mathrm{~F} 3$ & 1.78 & 1.24 & 1.24 & 0.86 & 0.71 & 0.60 & 0.85 & 0.61 & 0.93 & 0.57 & 1.32 & 0.95 \\
$\mathrm{C} 3$ & 1.10 & 0.76 & 0.77 & 0.55 & 0.53 & 0.48 & 0.49 & 0.52 & 0.65 & 0.76 & 1.39 & 1.00 \\
$\mathrm{P} 3$ & 0.72 & 0.59 & 0.47 & 0.39 & 0.47 & 0.42 & 0.44 & 0.43 & 0.56 & 0.41 & 0.62 & 0.48 \\
$\mathrm{Pz}$ & 0.95 & 0.96 & 0.71 & 0.71 & 0.48 & 0.54 & 0.50 & 0.51 & 0.63 & 0.64 & 0.69 & 0.70 \\
$\mathrm{P} 4$ & 0.80 & 0.75 & 0.54 & 0.50 & 0.44 & 0.51 & 0.52 & 0.60 & 0.50 & 0.54 & 0.58 & 0.64 \\
$\mathrm{C} 4$ & 0.97 & 0.88 & 0.72 & 0.71 & 0.49 & 0.64 & 0.55 & 0.72 & 0.55 & 0.75 & 1.06 & 0.90 \\
$\mathrm{~F} 4$ & 1.80 & 1.47 & 1.20 & 1.09 & 0.59 & 0.79 & 0.89 & 0.59 & 0.67 & 0.60 & 0.80 & 1.02 \\
$\mathrm{~F} 7$ & 5.67 & 5.45 & 3.29 & 2.95 & 1.48 & 1.60 & 1.92 & 1.22 & 1.56 & 1.31 & 3.32 & 2.39 \\
$\mathrm{~T} 3$ & 3.26 & 2.50 & 1.92 & 1.75 & 0.95 & 1.22 & 1.35 & 0.91 & 1.95 & 1.44 & 3.85 & 2.48 \\
$\mathrm{~T} 5$ & 1.75 & 1.89 & 1.21 & 1.48 & 1.00 & 1.40 & 1.15 & 1.39 & 1.78 & 1.47 & 1.54 & 1.48 \\
O1 & 1.93 & 1.66 & 1.28 & 1.05 & 0.64 & 0.72 & 0.79 & 0.65 & 1.05 & 0.84 & 2.19 & 1.38 \\
O2 & 1.88 & 1.58 & 1.26 & 0.99 & 1.04 & 0.83 & 0.89 & 0.91 & 0.94 & 0.86 & 1.33 & 1.40 \\
T6 & 2.46 & 2.00 & 1.27 & 1.41 & 1.08 & 1.37 & 0.93 & 1.47 & 1.87 & 1.46 & 1.82 & 1.84 \\
T4 & 2.25 & 2.64 & 1.38 & 1.42 & 1.09 & 1.19 & 1.23 & 0.97 & 1.84 & 1.35 & 3.27 & 2.38 \\
F8 & 5.56 & 5.46 & 2.68 & 2.54 & 1.37 & 1.50 & 1.69 & 1.10 & 1.51 & 1.35 & 2.65 & 2.47 \\
Med & 1.71 & 1.57 & 1.22 & 0.97 & 0.80 & 0.77 & 0.81 & 0.67 & 0.93 & 0.79 & 1.32 & 1.25 \\
\hline
\end{tabular}




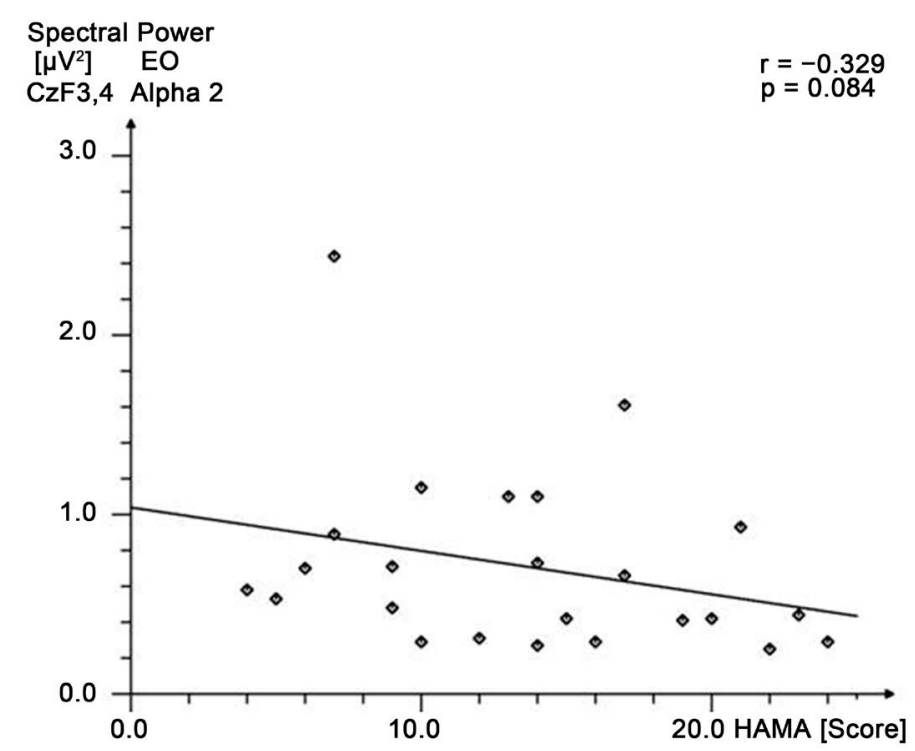

Figure 3. Correlation between HAMA anxiety questionnaire (score on abscissa) and spectral alpha2 power during the recording condition "eyes open" before drug intake. Spectral power was averaged including $\mathrm{C}_{\mathrm{z}}, \mathrm{F}_{3}$ and $\mathrm{F}_{4}$ electrodes. Correlation coefficient $(\mathrm{r}=-0.329 ; \mathrm{p}=0.084)$.

emotional challenges lead to consistent changes of spectral power. For this purpose, data from each challenge were averaged over the presentation time in order to follow each of the brain regions with respect to the pattern of spectral power changes with respect to each frequency. In order to evaluate challenge specific changes of spectral power each challenge was calculated against the "eyes open" condition in order to eliminate unspecific responses. As expected, highly statistically significant increases of spectral power in the delta, theta and beta range were observed during all challenges. An overview on the statistical significance of the regional distribution of spectral power enhancement in comparison to the recording condition "eyes open" is documented in Figure 4(a) and Figure 4(b) for cognitive challenges and Figure 5(a) and Figure 5(b) for emotional challenges.

There is wide believe that the two brain hemispheres can function independently from each other. We therefore have analyzed the frequency changes in the presence of all challenges for each hemisphere in separate. The result is documented in Table 6 and Table 7. In general, the challenges led to statistically significant increases of delta (occasionally also theta) and beta2 spectral power in comparison to the recording condition "eyes open". As one can see, there are some differences like the extent of delta and beta2 spectral power under the recording condition "eyes open". During presentation of emotional pictures higher beta2 power is seen in the left hemisphere. Watching the examination video clip also leads to stronger enhancement of beta2 power in the left hemisphere. The largest difference with respect to beta2 power between the hemispheres was observed during the horror video. Regarding now the effects of all challenges with respect to single hemispheres strongest involvement of delta waves is recognized in both hemispheres. 
Picture Comparison / Eyes Open
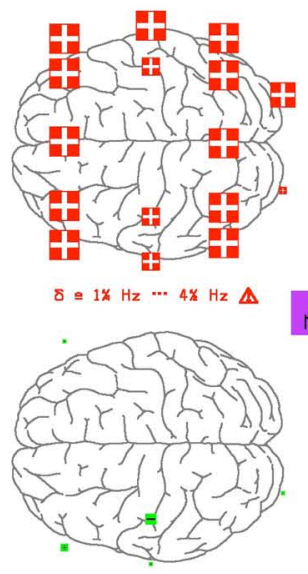

$\alpha_{2} \cong 9 x_{\mathrm{Hz}} \cdots 12 \mathrm{~Hz} \mathrm{~Hz}$
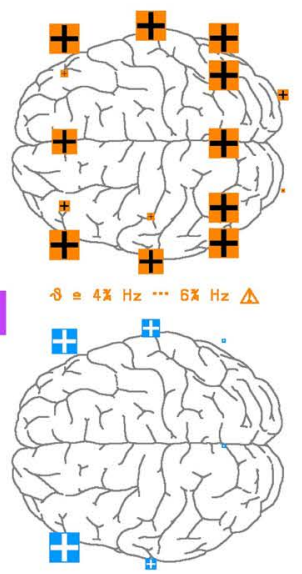

$\beta_{1} \cong 12 \% \mathrm{~Hz} \cdots 18 \% \mathrm{~Hz} \Delta$

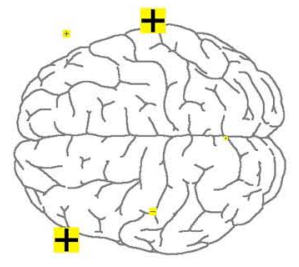

$v^{2}$

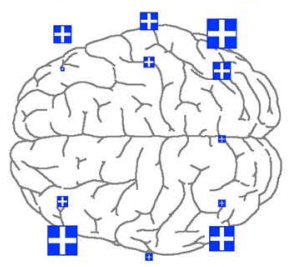

$\beta_{2} \cong 18 \% \mathrm{~Hz} \cdots 35 \mathrm{~Hz} \triangle$

\section{Stroop - Test / Eyes Open}
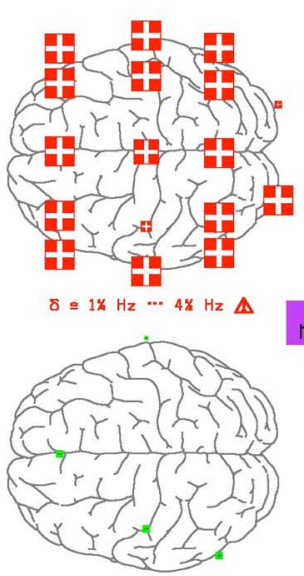

$\alpha_{2} \subseteq 9 \% \mathrm{~Hz} \cdots 12 \% \mathrm{~Hz} \Delta$
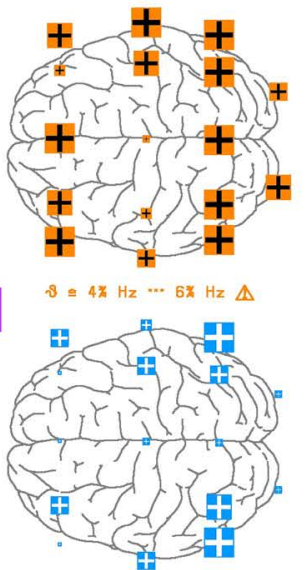

$\beta_{1} \cong 12 \% \mathrm{~Hz} \cdots 18 \% \mathrm{~Hz} \triangle$

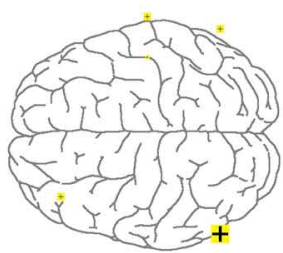

$v^{2}$

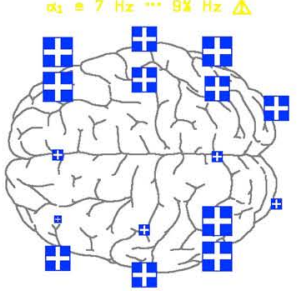

$\beta_{2} \cong 18 \% \mathrm{~Hz} \cdots 35 \mathrm{~Hz} \triangle$

\section{Memory - Test / Eyes Open}
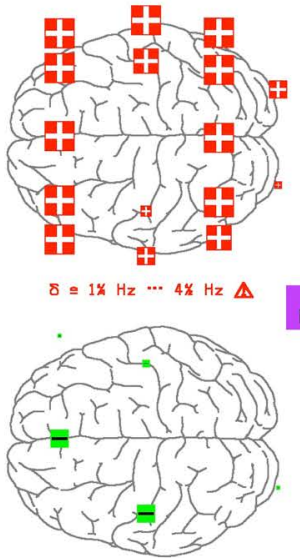

$\alpha_{2} \cong 9 \% \mathrm{~Hz} \cdots 12 \% \mathrm{~Hz} \triangle$

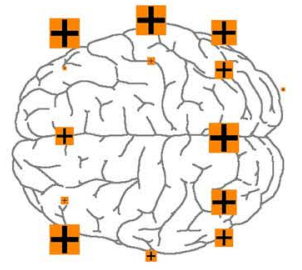

$\mathrm{s}=4 \% \mathrm{~Hz} \cdots$ 6\% Hz

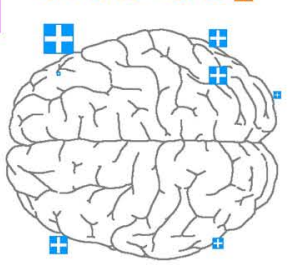

$\beta_{1} \cong 12 \% \mathrm{~Hz} \cdots 18 \% \mathrm{~Hz} \triangle$

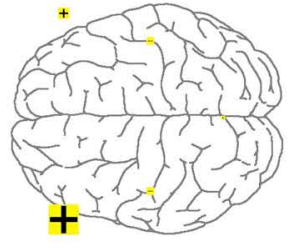

$V^{2}$

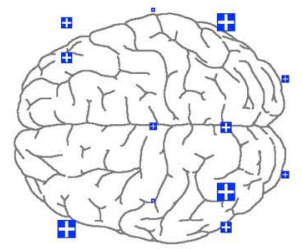

$\beta_{2} \cong 18 \mathrm{~Hz} \cdots 35 \mathrm{~Hz} \triangle$

- $\mathbf{p}<0.10$

$p<0.05 \square p<0.01$ $p<0.002$ $\mathbf{p}<0.001$

(a) 


\section{CPT - Test / Eyes Open}
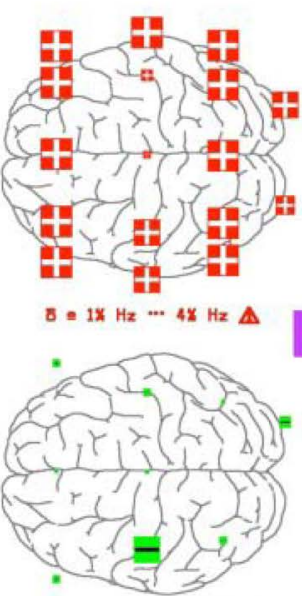

$\alpha_{2}=9 x H_{2} \cdots 12 X H_{2} \triangle$

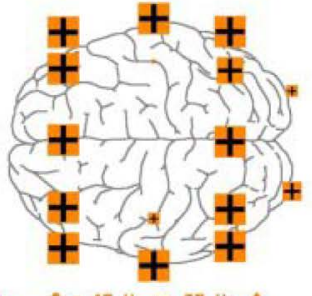

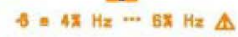

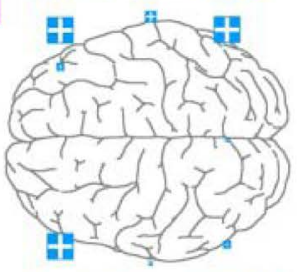

$\beta_{1}=12 \pi \mathrm{Hz} \cdots 18 \times \mathrm{Hz} \triangle$

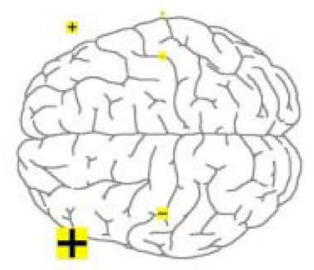

$v^{2}$

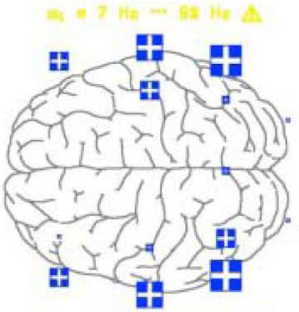

$B_{2}=18 \times \mathrm{Hz} \cdots 95 \mathrm{~Hz} \triangle$

\section{Brain Teaser / Eyes Open}
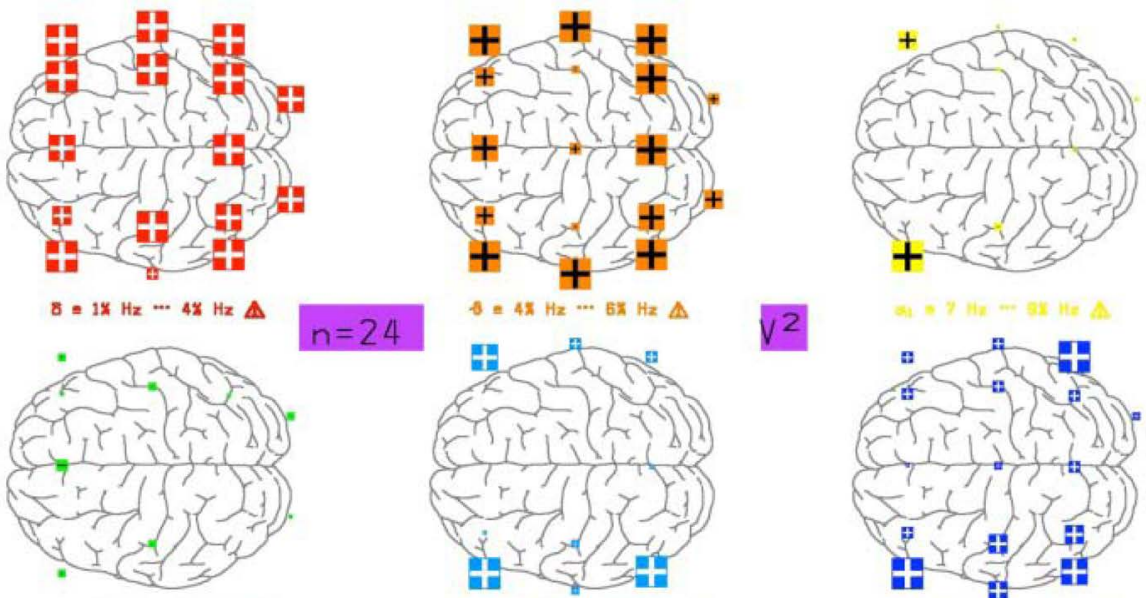

$v^{2}$

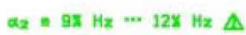

$\beta_{1}=12 \mathrm{Kz}=1 \mathrm{BX} \mathrm{Hz} \triangle$

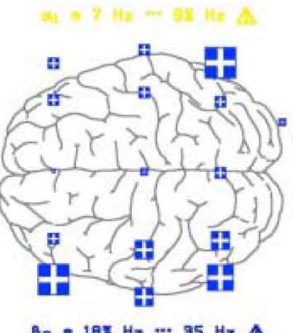

- $\mathrm{p}<0.10$

$\mathrm{p}<0.05$

$\mathbf{p}<0.01$

$p<0.002$

$\mathrm{p}<0.001$

(b)

Figure 4. Statistical maps for the regional significance of spectral frequency changes during performance of cognitive tasks. Statistical significance (sign-test) in comparison to the relaxed state is documented by the size of the small boxes (lowest part of the image).

\section{Efficacy of Calmvalera Hevert Tablets on Challenge Induced Spectral Frequency Changes}

\subsection{Documentation of Spectral Changes at Single Scenes of the Challenges}

First impressions of the effectiveness of Calmvalera Hevert tablets are obtained during single scenes of the presented challenges like emotional images (example: Figure 6), video clips (example: Figure 7). In order to uncover the influence of Calmvalera Hevert tablets under the different recording conditions identical single scenes were docu- 
Fix Cross / Eyes Open
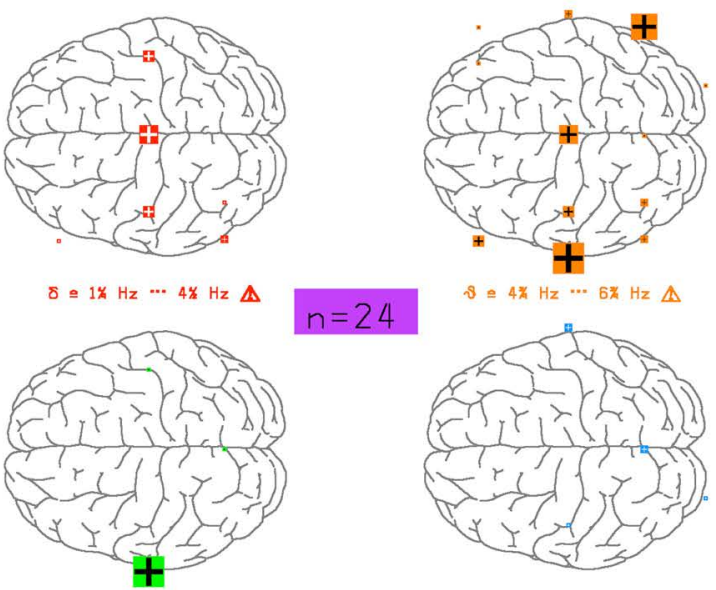

$n=24$

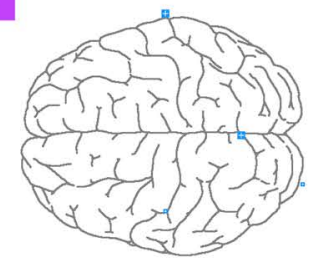

$\beta_{1} \cong 12 \% \mathrm{~Hz} \cdots 18 \% \mathrm{~Hz} \triangle$

$\alpha_{2}=9 \% \mathrm{~Hz} \cdots 12 \% \mathrm{~Hz} \triangle$

Emotion Pictures / Eyes Open
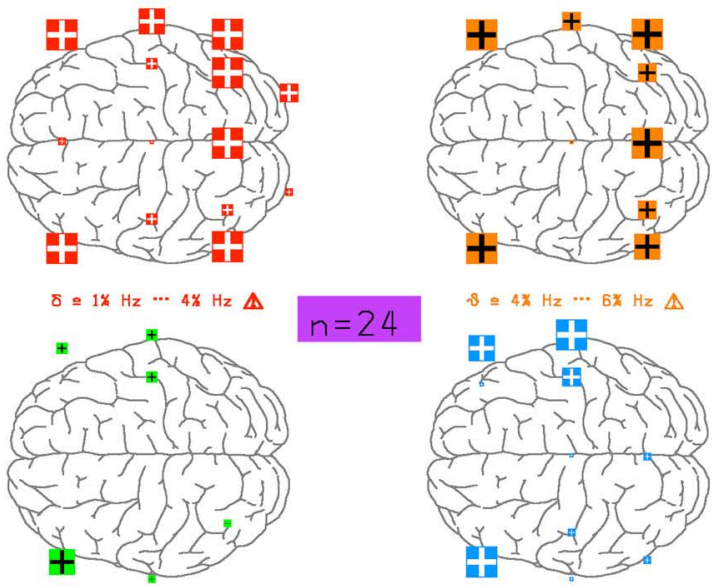

$\alpha_{2} \cong 9 w_{m} \mathrm{~Hz} \cdots 12 \% \mathrm{~Hz} \triangle$

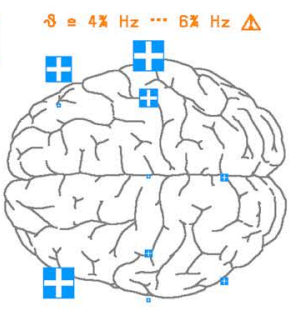

$\beta_{1} \cong 12 \% \mathrm{~Hz} \cdots 18 \% \mathrm{~Hz} \Delta$

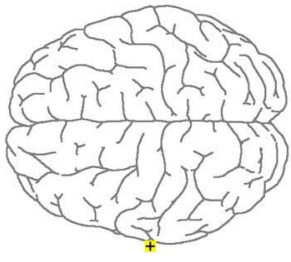

$v^{2}$

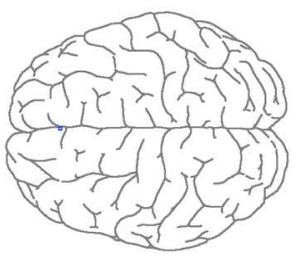

$\beta_{2} \cong 18 \% \mathrm{~Hz} \cdots 35 \mathrm{~Hz} \triangle$
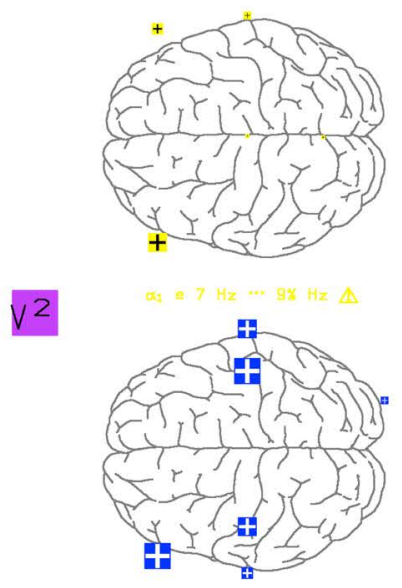

$\beta_{2} \cong 18 \% \mathrm{~Hz} \cdots 35 \mathrm{~Hz} \triangle$

\section{Exam Anxiety / Eyes Open}

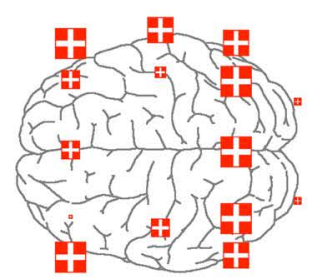

$\delta \cong 1 \% \mathrm{~Hz} \cdots 4 \% \mathrm{~Hz}$

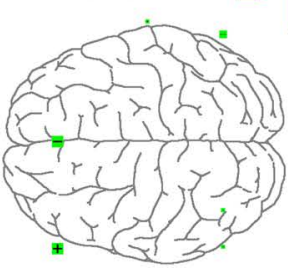

$\alpha_{2} \cong 9 \% \mathrm{~Hz} \cdots 12 \% \mathrm{~Hz} \triangle$
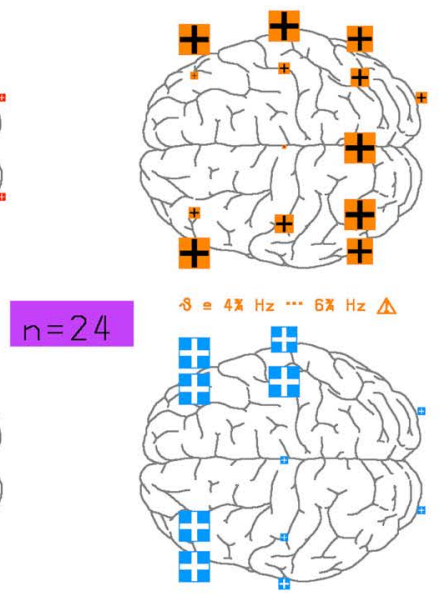

$\beta_{1} \cong 12 \% \mathrm{~Hz} \cdots 18 \% \mathrm{~Hz} \triangle$

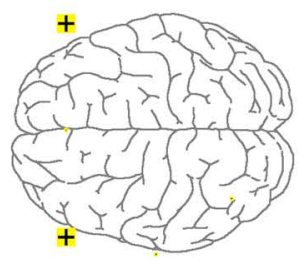

- $\mathbf{p}<\mathbf{0 . 1 0}$

$\mathrm{p}<0.05$

$\mathbf{p}<0.01$

$\mathbf{p}<0.002$

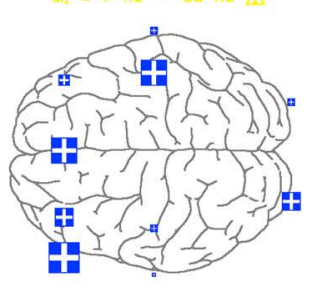

$\beta_{2} \cong 18 \% \mathrm{~Hz} \cdots 35 \mathrm{~Hz} \Delta$

(a) 


\section{Dentist Pain / Eyes Open}

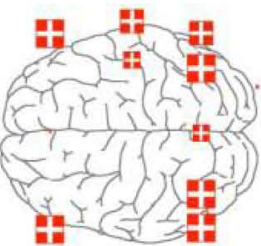

$\delta=1 \times \mathrm{Hz}_{2} \ldots \mathrm{AX} \mathrm{Hz} \mathrm{A}$

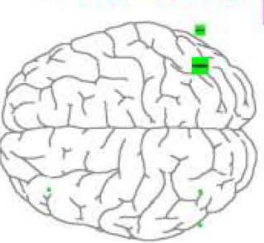

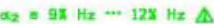

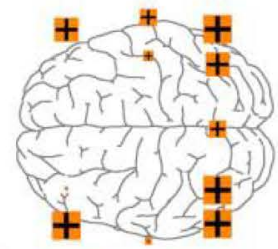

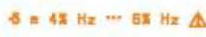

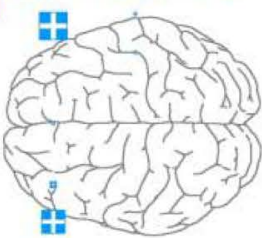

$\beta_{1}=12 \mathrm{~Hz}_{\mathrm{z}} \cdots 1 \mathrm{Ez} \mathrm{Hz} \mathbb{A}$

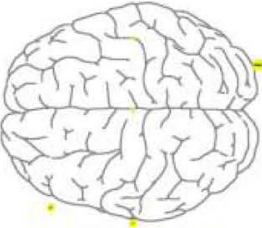

$v^{2}$

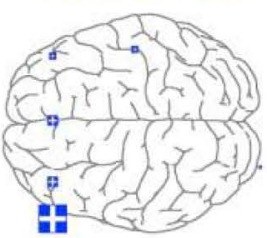

$\mathrm{Az}_{\mathrm{z}}=18 \mathrm{~Hz} \cdots 35 \mathrm{~Hz} \triangle$

\section{Horror-OP / Eyes Open}
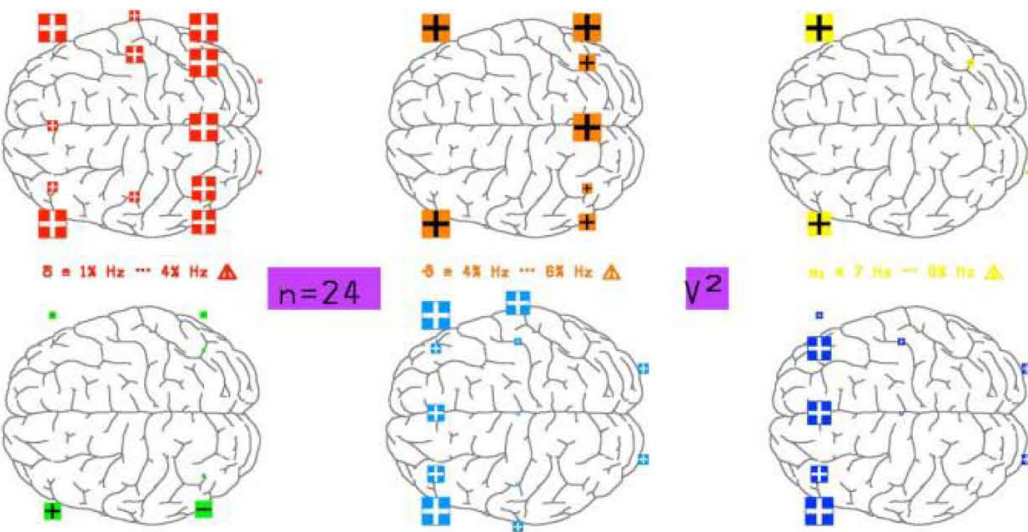

$v^{2}$

Fe $=9 \mathrm{~Hz}+12 \mathrm{~Hz} \mathrm{~Hz}$

$\beta_{1}=12 \mathrm{~K} H z \cdots$ 18X $\mathrm{Hz}_{2} \mathrm{~A}$

Horror Video / Eyes Open

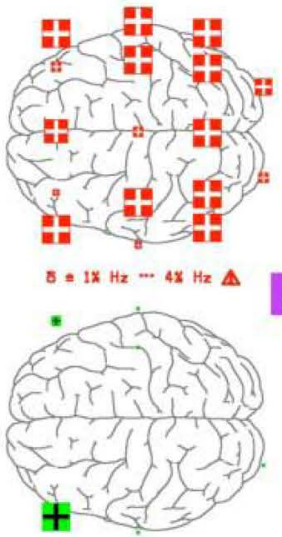

wz $=$ ax $\mathrm{Hz} \cdots 12 \mathrm{~Hz} \Delta$
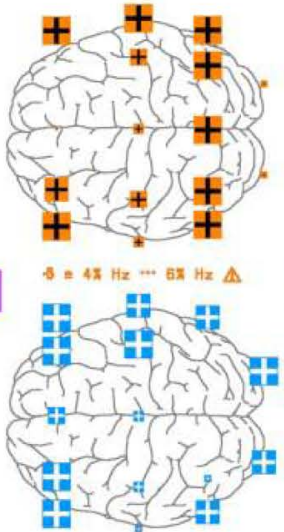

$B_{1}=12 \mathrm{~Hz}_{\mathrm{H}} \cdots 1 \mathrm{BX} \mathrm{Hz} \mathbb{A}$

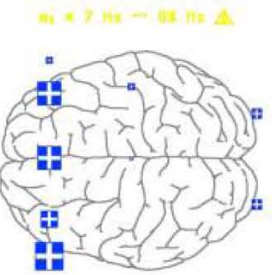

$\beta_{2}=18 \mathrm{~Hz} \cdots 35 \mathrm{~Hz} \triangle$

- $p<0.10$
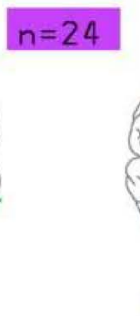

$p<0.05$

$\mathbf{p}<\mathbf{0 . 0 1}$

(b)

Figure 5. Statistical maps for the regional significance of spectral frequency changes during emotional challenges. Statistical significance (sign-test) in comparison to the relaxed state is documented by the size of the small boxes (lowest part of the image). 
Table 6. Overview on changes in spectral power induced by all challenges with respect to all frequencies. Data are given in $\mu \mathrm{V}^{2}$ for the left brain area (combination of all left side electrodes $\mathrm{F}_{3,7} \mathrm{~T}_{3,5} \mathrm{P}_{3} \mathrm{C}_{3} \mathrm{O}_{1}$ ). Statistical significance (sign-test) in comparison to "eyes open" recording condition is indicated as " $\mathrm{p}<$ " beneath the spectral power given in $\mu \mathrm{V}^{2}$.

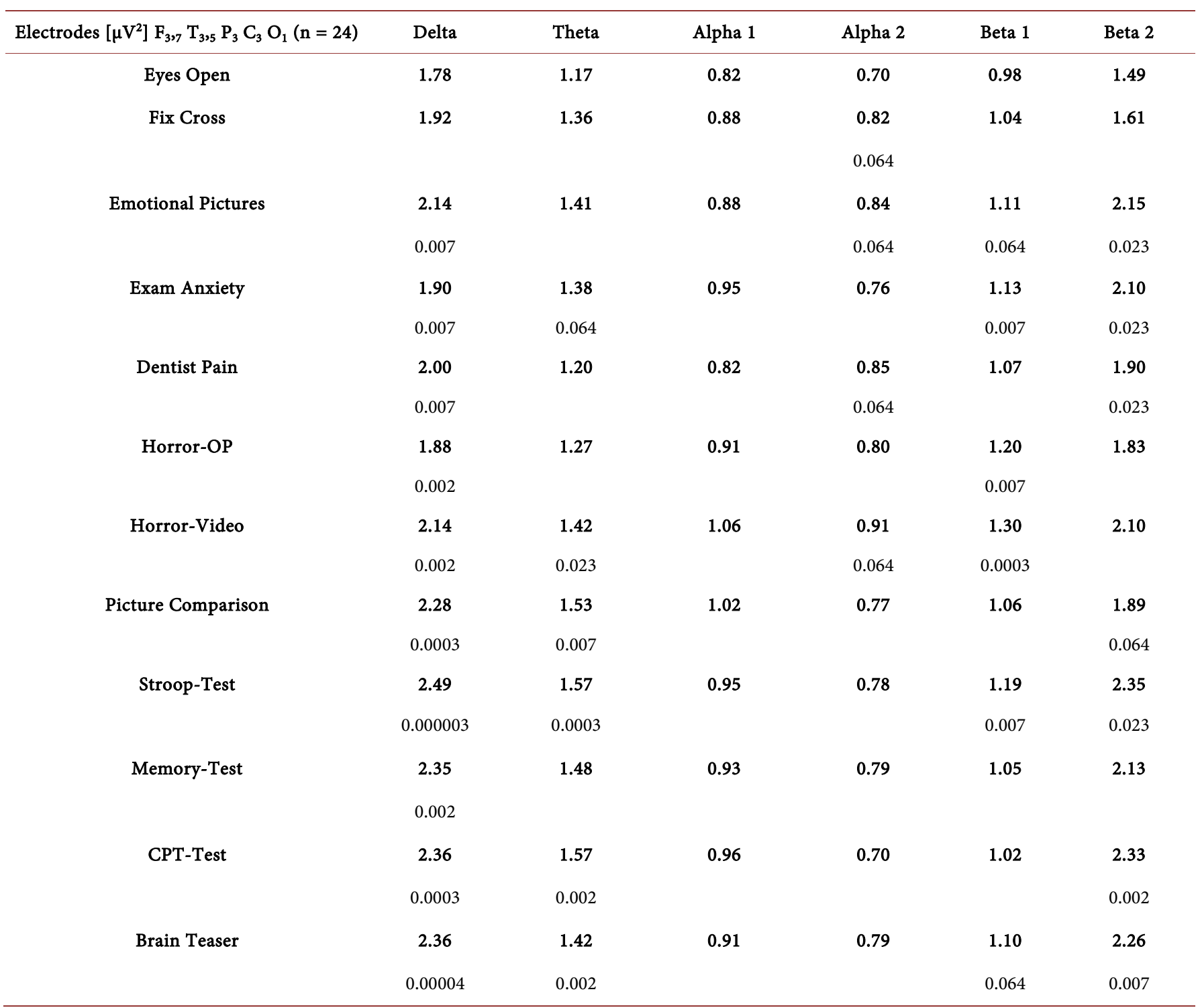

mented before and after intake of the drug. The spectral power of all regions was looked at in terms of possible changes. A first impression was that alpha1 as well as alpha2 spectral power had increased in regions like the temporal lobe (yellow bars in Figure 6). An example recorded during watching the video "the dentist" is documented in Figure 7. Here stronger alphal activity is seen at central and temporal regions.

\subsection{Group Analysis of Spectral Changes in the Presence of Calmvalera Hevert Tablets with Respect to Single Challenges}

Quantitative analysis of frequency changes induced by Calmvalera Hevert tablets with respect to different brain regions revealed a statistically significant increase of apha1 
Table 7. Overview on changes in spectral power induced by all challenges with respect to all frequencies. Data are given in $\mu \mathrm{V}^{2}$ for the right brain hemisphere (combination of all right side electrodes $F_{4,8} T_{4,6} P_{4} C_{4} O_{2}$ ). Statistical significance (sign-test) in comparison to "eyes open" recording condition is indicated as " $\mathrm{p}<$ " beneath the spectral power given in $\mu \mathrm{V}^{2}$.

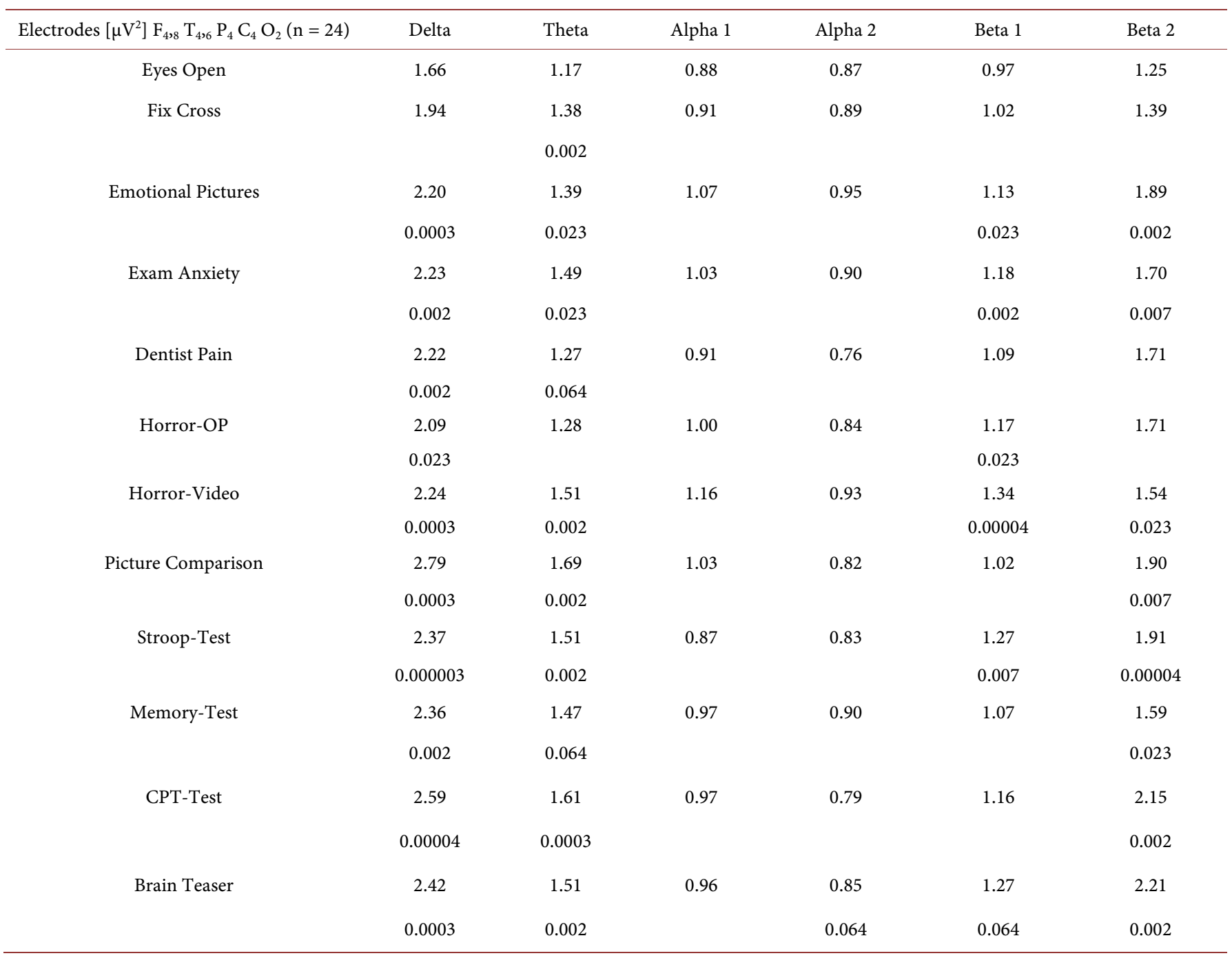

and alpha2 spectral power at electrode positions $\mathrm{F}_{3}, \mathrm{C}_{3}, \mathrm{P}_{3}, \mathrm{~T}_{3}$ and $\mathrm{O}_{1}$ already under the recording condition "eyes open" as depicted in Figure 8. Remarkably, these electrode positions represent all areas on the left hemisphere (uneven numbers). There are also minor increases on the right hemisphere (even numbers) but none became statistically significant. Colors of the maps shift into a more yellow green direction as consequence of increased alpha activity.

When subjects were concentrating their attention on a fixation cross for one minute again alpha1 and alpha2 spectral power increases emerged nearly at the same electrode positions plus at $\mathrm{F}_{4}$ and $\mathrm{F}_{8}$ on the right hemisphere in a significant manner in comparison to placebo. An overview is given in Figure 9. Again colors of the maps shift into a more yellow green direction as consequence of increased alpha activity stronger within the left hemisphere (right side). 


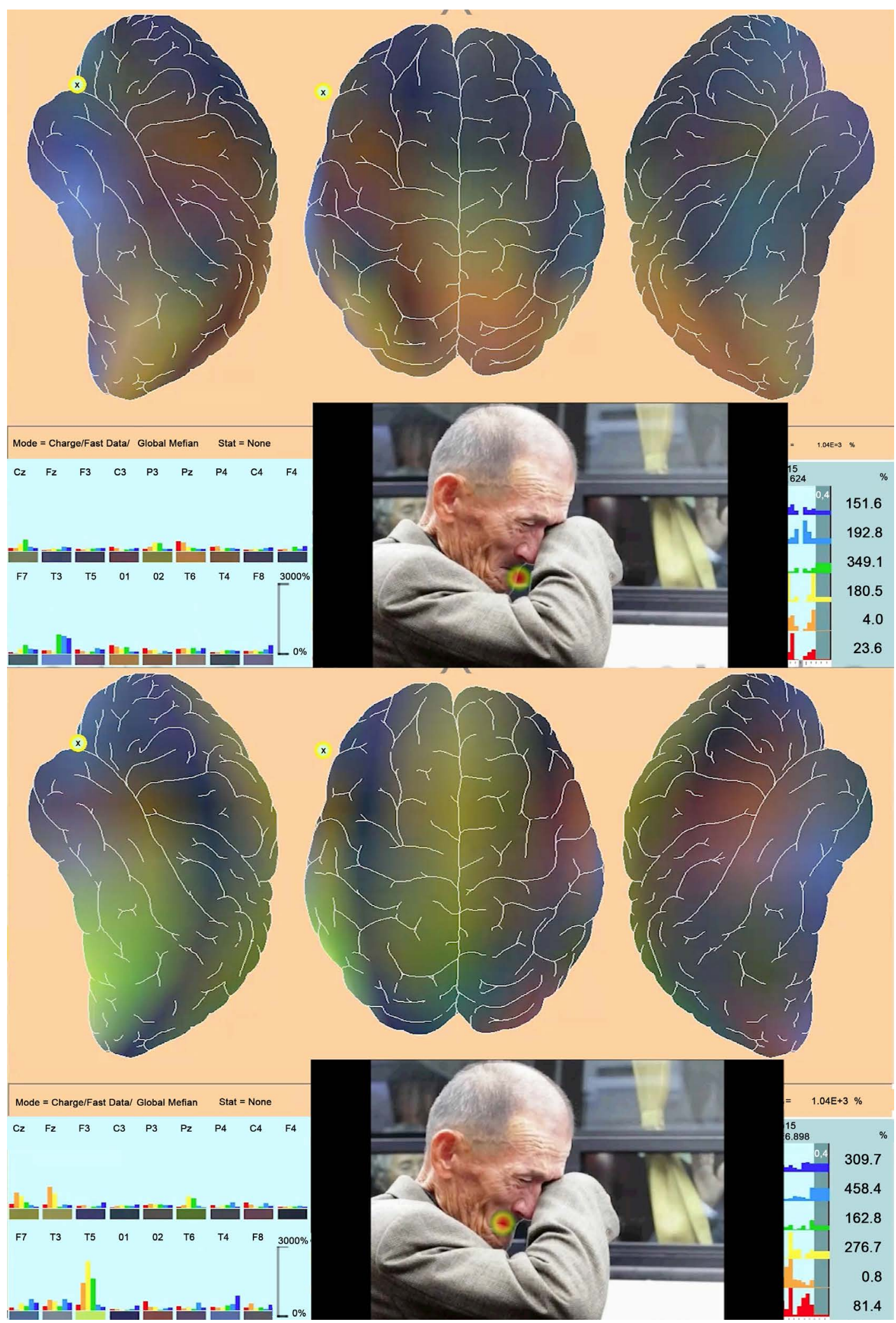

Figure 6. Representative scene (364 ms) from an emotional picture (upper image: at baseline $(0 \mathrm{~h})$ ), lower image: 90 min after intake of 6 tablets of Calmvalera Hevert (group verum subject 003). Note increase of alpha power at electrode position $\mathrm{T}_{5}$. 


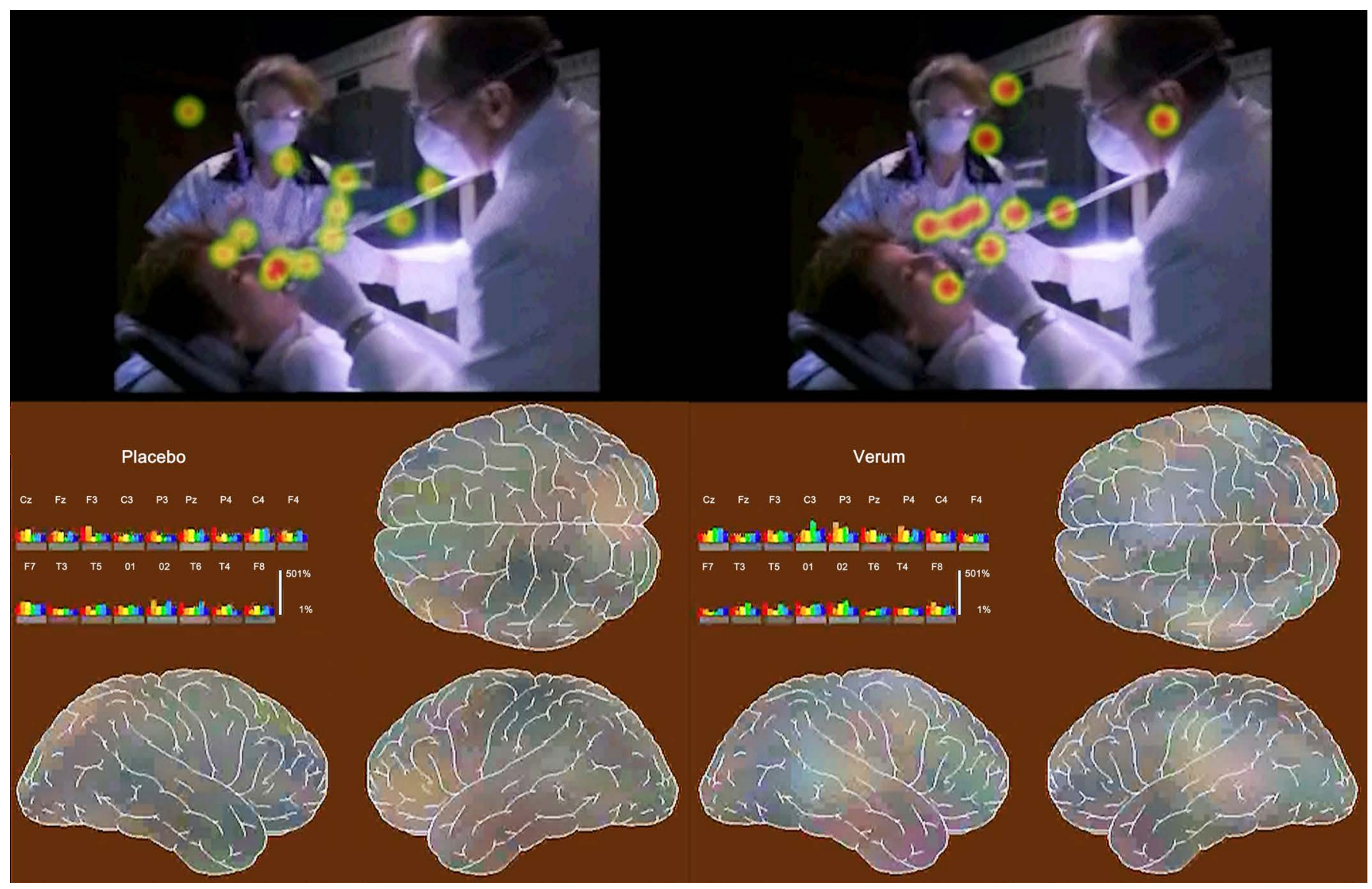

Figure 7. Comparison of an arbitrarily chosen but representative single scene (364 ms). Data were averaged for all 12 subjects of the placebo group (left images) and verum group (right images). Eye-track results are depicted in the upper windows as so-called "heatmap". EEG data are depicted in the lower windows. Frequency changes are documented within the bar graphs. Delta waves are coded into red, theta into orange, alpha1 into yellow, alpha 2 into green, beta1 into turquoise, beta2 into blue. Please note decrease of beta (blue) and increase of alpha1 power (yellow) after intake of Calmvalera Hevert tablets (right image).

A very similar pattern was observed when watching the video "at the dentist". Highest increases of alpha spectral power appeared at electrode position $\mathrm{C}_{3}$, followed by $\mathrm{F}_{3}$ and $\mathrm{O}_{1}$. Under this recording condition also $\mathrm{P}_{\mathrm{z}}$ and $\mathrm{T}_{6}$ showed very slight, but statistically significant increases as documented in Figure 10. Due to increases of alpha activity dominant prevalence of yellow-green colors is observed within the left hemisphere (map right side of the image).

Analysis of the spectral power changes during watching the video dealing with an emergency surgery in the bush (Horror-OP) again revealed largest increases of alpha2 power at electrode positions $\mathrm{C}_{3}$ and $\mathrm{O}_{1}$. Minor but still significant increases were seen at $\mathrm{C}_{4}, \mathrm{O}_{2}$ and $\mathrm{T}_{6}$. An overview on changes with respect to all brain areas is given in Figure 11. Please note yellow-green spot in the map due to stronger focal alpha activity.

During performance of a cognitive task like the "Picture Comparison" again electrode positions $\mathrm{C}_{3}$ and $\mathrm{O}_{1}$ showed high statistically significant increases of alpha power. In addition, some increase of beta power emerged at electrode positions $\mathrm{C}_{3}, \mathrm{~T}_{3}$ and $\mathrm{O}_{1}$. Data are documented in Figure 12. With respect to the map increased alpha activity is 


\section{Eyes Open}
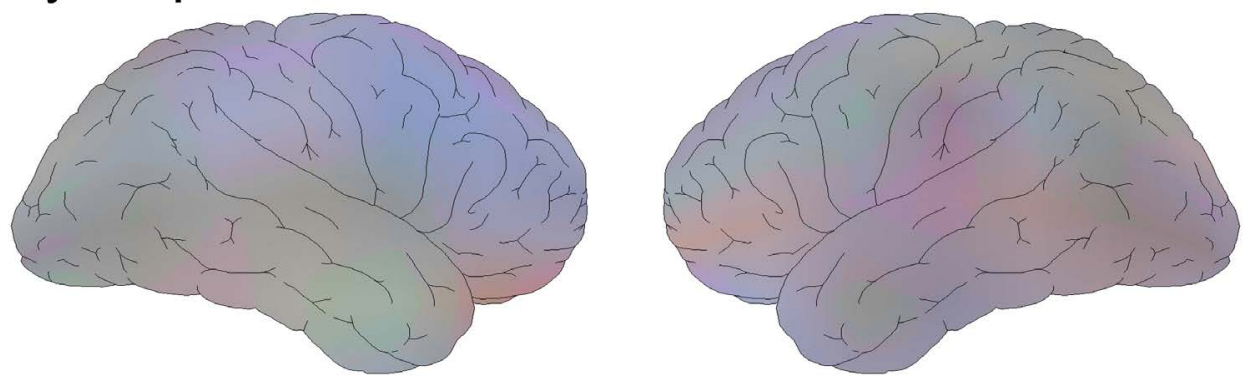

\section{Placebo}

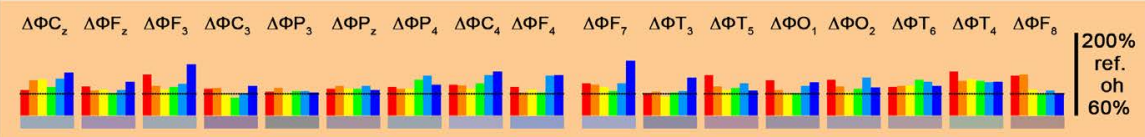

\section{Verum}
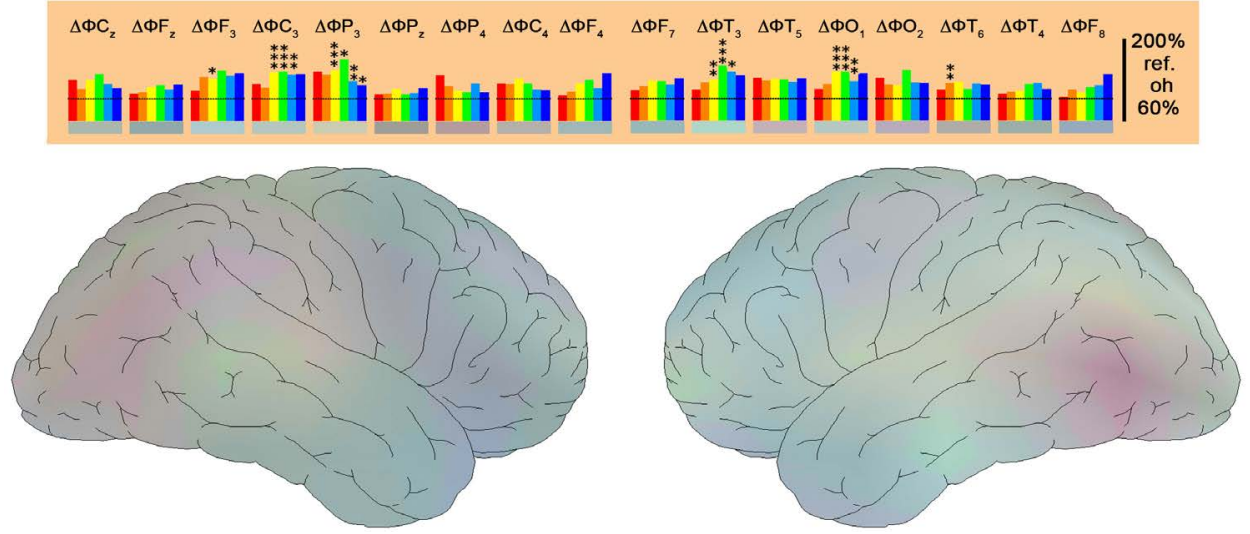

Figure 8. Spectral power differences (recording condition "eyes open") in comparison to the predrug period (set to $100 \%$ ) 90 min after intake of placebo or verum (Calmvalera Hevert tablets) in all brain regions represented by the electrode positions: $\mathrm{C}=$ central, $\mathrm{P}=$ parietal, $\mathrm{O}=$ occipital, $\mathrm{F}$ $=$ frontal, $\mathrm{T}=$ temporal. Even numbers are located in the right hemisphere, uneven numbers in the left one. Frequencies: red $=$ delta, orange $=$ theta, yellow $=$ alpha1, green $=$ alpha2, turquoise $=$ beta 1 and blue $=$ beta2. Statistical significance (wilcoxon-test) between placebo and verum is indicated by stars. ${ }^{*}=\mathrm{p}<0.10 ;{ }^{* *}=\mathrm{p}<0.05 ;{ }^{* *}=\mathrm{p}<0.01$.

observed in frontal parts of the brain at interpolated regions indicated by predominating yellow and/or green color (more in the left hemisphere).

\subsection{Effect of Calmvalera Hevert on the Spectral Power with Respect to Brain Hemispheres}

Since right and left hemisphere reacted in a somewhat quantitatively different way to several challenges, they were analyzed separately with respect to an action of Calmvalera Hevert tablets in comparison to placebo. Regarding spectral delta and theta spectral activity virtually no effects were seen except for a tiny increase of theta power when watching emergency surgery (Horror-OP). Strongest statistically significant changes were observed in the alpha frequencies during several challenges as depicted in Figure 13 for the left hemisphere. However, there were also some minor but statistically sig- 


\section{Fix Cross}
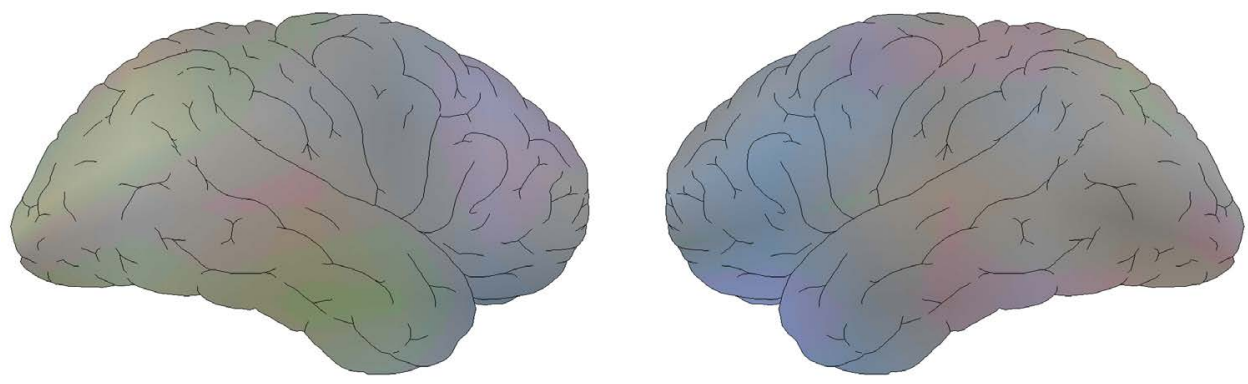

Placebo

$\Delta \Phi C_{2} \quad \Delta \Phi F_{2} \quad \Delta \Phi F_{3} \quad \Delta \Phi C_{3} \quad \Delta \Phi P_{3} \quad \Delta \Phi P_{2} \quad \Delta \Phi P_{4} \quad \Delta \Phi C_{4} \quad \Delta \Phi F_{4} \quad \Delta \Phi F_{7} \quad \Delta \Phi T_{3} \quad \Delta \Phi T_{5} \quad \Delta \Phi O_{1} \quad \Delta \Phi O_{2} \quad \Delta \Phi T_{6} \quad \Delta \Phi T_{4} \quad \Delta \Phi F_{8}$

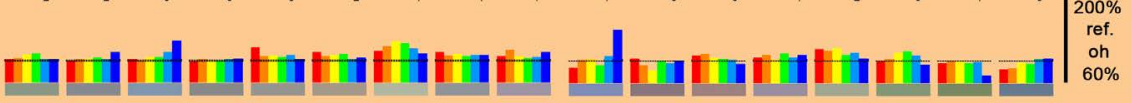

\section{Verum}
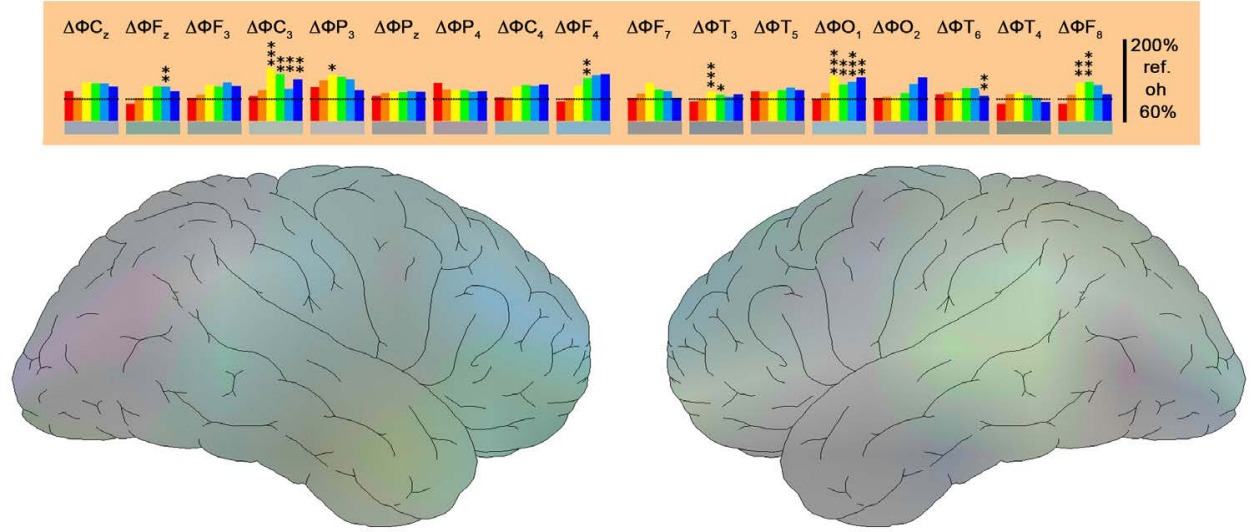

Figure 9. Spectral power differences (recording condition "fix cross") in comparison to the predrug period (set to $100 \%$ ) 90 min after intake of placebo or verum (Calmvalera Hevert tablets) in all brain regions represented by the electrode positions: $\mathrm{C}=$ central, $\mathrm{P}=$ parietal, $\mathrm{O}=$ occipital, $\mathrm{F}$ $=$ frontal, $\mathrm{T}=$ temporal. Even numbers are located in the right hemisphere, uneven numbers in the left one. Frequencies: red $=$ delta, orange $=$ theta, yellow $=$ alpha1, green $=$ alpha2, turquoise $=$ beta 1 and blue $=$ beta2. Statistical significance (wilcoxon-test) between placebo and verum is indicated by stars. ${ }^{*}=\mathrm{p}<0.10 ;{ }^{* *}=\mathrm{p}<0.05 ;{ }^{* *}=\mathrm{p}<0.01$.

nificant increases of beta 1 power and one result in beta2 power. Statistically significant spectral changes within the right hemisphere were only observed in the alpha1 range during watching the fix cross $(\mathrm{p}<0.1)$, in the alpha2 range during watching the fix cross $(\mathrm{p}<0.05)$ and the horror video $(\mathrm{p}<0.05)$. Finally, betal spectral power had increased again during looking at the fix cross $(\mathrm{p}<0.1)$.

\subsection{Discriminant Analysis of Whole Data Set with Comparison to Other Drugs}

Finally, all 102 parameters ( 17 electrode positions $\times 6$ frequency ranges) were fed into a linear discriminant analysis for comparison with other drugs. As documented in Figure 14 the effect of Calmvalera Hevert tablets (verum) was projected at a considerable distance to the effect of its placebo (Figure 13) proving its fast effectiveness within $90 \mathrm{~min}$ 


\section{Dentist Pain}
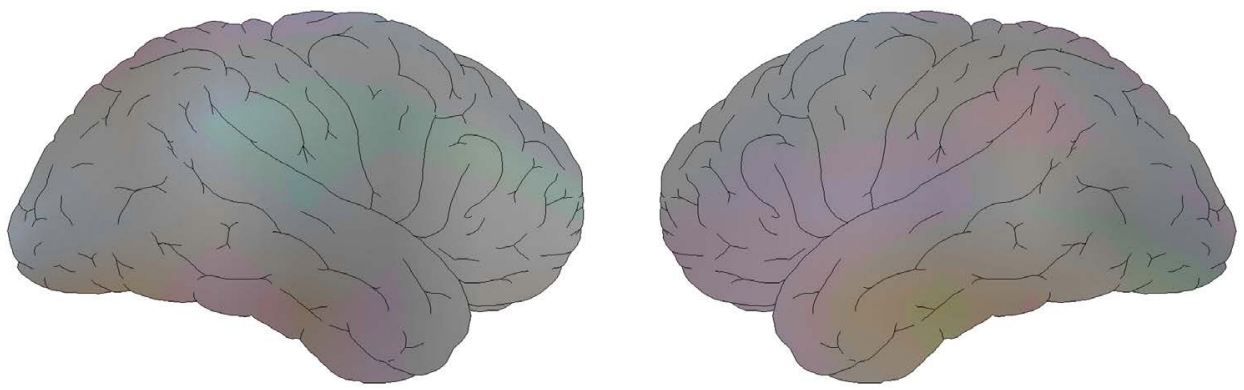

\section{Placebo}

$\Delta \Phi C_{z} \quad \Delta \Phi F_{z} \quad \Delta \Phi F_{3} \quad \Delta \Phi C_{3} \quad \Delta \Phi P_{3} \quad \Delta \Phi P_{z} \quad \Delta \Phi P_{4} \quad \Delta \Phi C_{4} \quad \Delta \Phi F_{4} \quad \Delta \Phi F_{7} \quad \Delta \Phi T_{3} \quad \Delta \Phi T_{5} \quad \Delta \Phi O_{1} \quad \Delta \Phi O_{2} \quad \Delta \Phi T_{6} \quad \Delta \Phi T_{4} \quad \Delta \Phi F_{8}$

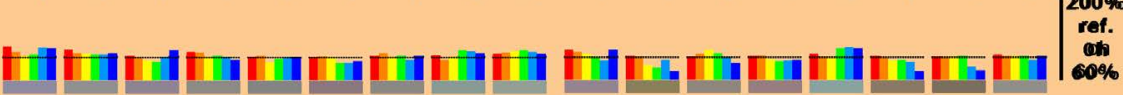

Verum

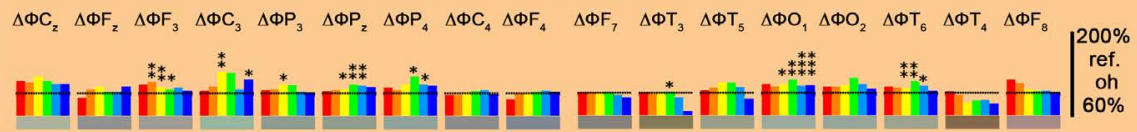
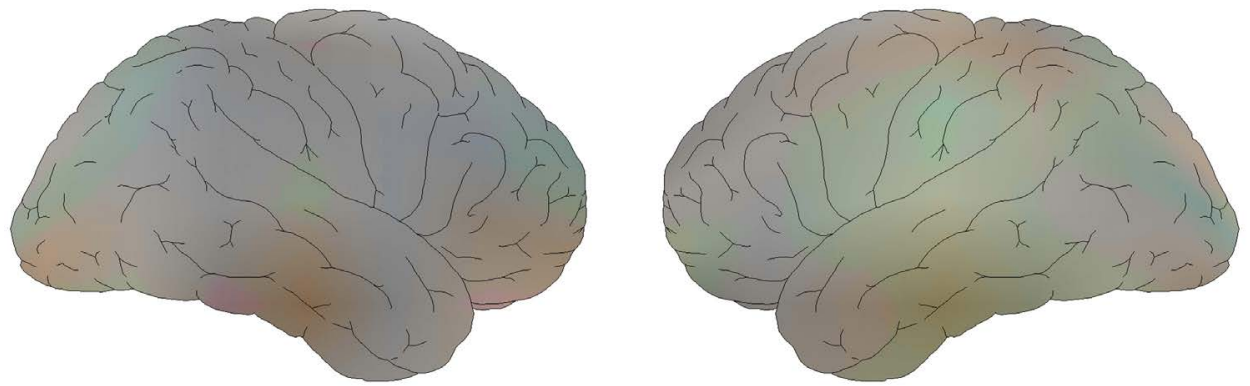

Figure 10. Spectral power differences (recording condition "dentist pain") in comparison to the pre-drug period (set to 100\%) 90 min after intake of placebo or verum (Calmvalera Hevert tablets) in all brain regions represented by the electrode positions: $\mathrm{C}=$ central, $\mathrm{P}=$ parietal, $\mathrm{O}=\mathrm{oc}-$ cipital, $\mathrm{F}=$ frontal, $\mathrm{T}=$ temporal. Even numbers are located in the right hemisphere, uneven numbers in the left one. Frequencies: red $=$ delta, orange $=$ theta, yellow $=$ alpha1, green $=$ alpha2, turquoise $=$ beta 1 and blue $=$ beta2. Statistical significance (wilcoxon-test) between placebo and verum is indicated by stars. ${ }^{\star}=\mathrm{p}<0.10 ;^{\star *}=\mathrm{p}<0.05 ;{ }^{\star *}=\mathrm{p}<0.01$.

after intake. Interestingly, another homeopathic drug (Neurexan $\left.{ }^{\circledR}\right)$ and a plant derived preparation $\left(\right.$ Neuravena $\left.^{\circledR}\right)$, both prescribed for the same indication as Calmvalera Hevert tablets, are projected into close vicinity of Calmvalera Hevert tablets (verum in Figure 14).

\section{Effect of Calmvalera Hevert on Performance of Psychometric Tasks}

Analysis of the performance of the psychometric tests did not reveal an influence of Calmvalera Hevert tablets when comparing to baseline values or after intake of placebo or verum as documented in Table 8. Slightly higher values after intake of the preparations were not statistically significantly different in any of the groups. 


\section{Horror OP}
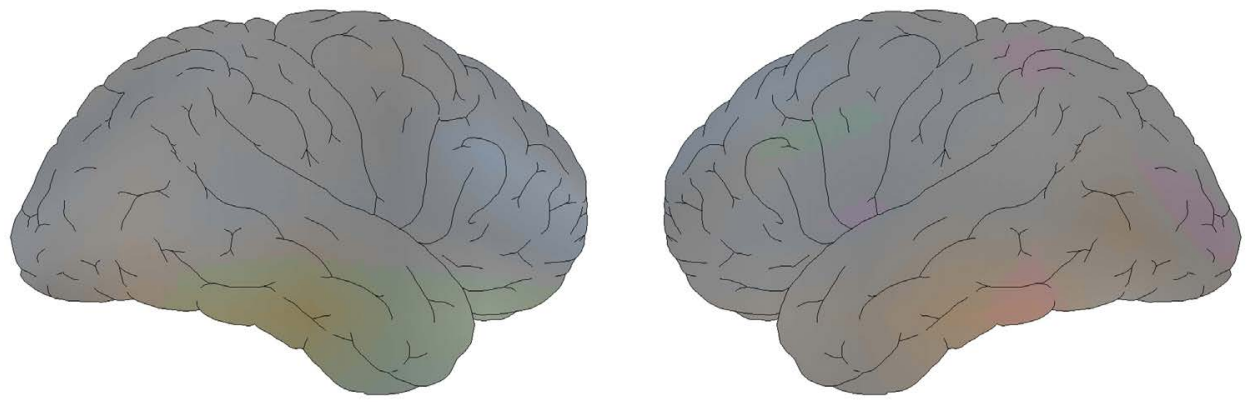

\section{Placebo}

$\Delta \Phi C_{2} \quad \Delta \Phi F_{2} \quad \Delta \Phi F_{3} \quad \Delta \Phi C_{3} \quad \Delta \Phi P_{3} \quad \Delta \Phi P_{2} \quad \Delta \Phi P_{4} \quad \Delta \Phi C_{4} \quad \Delta \Phi F_{4} \quad \Delta \Phi F_{7} \quad \Delta \Phi T_{3} \quad \Delta \Phi T_{5} \quad \Delta \Phi O_{1} \quad \Delta \Phi O_{2} \quad \Delta \Phi T_{6} \quad \Delta \Phi T_{4} \quad \Delta \Phi F_{8}$

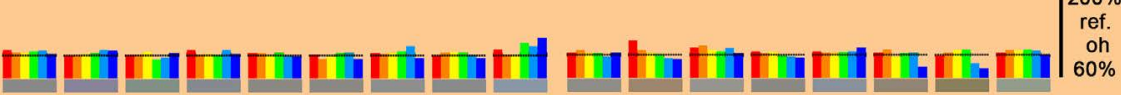

\section{Verum}

$\Delta \Phi C_{z} \quad \Delta \Phi F_{z} \quad \Delta \Phi F_{3} \quad \Delta \Phi C_{3} \quad \Delta \Phi P_{3} \quad \Delta \Phi P_{z} \quad \Delta \Phi P_{4} \quad \Delta \Phi C_{4} \quad \Delta \Phi F_{4} \quad \Delta \Phi F_{7} \quad \Delta \Phi T_{3} \quad \Delta \Phi T_{5} \quad \Delta \Phi O_{1} \quad \Delta \Phi O_{2} \quad \Delta \Phi T_{6} \quad \Delta \Phi T_{4} \quad \Delta \Phi F$

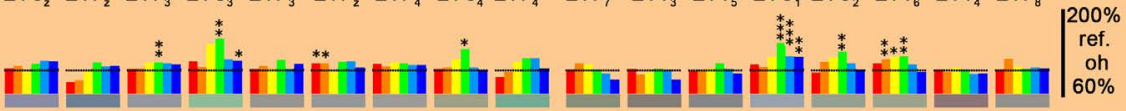
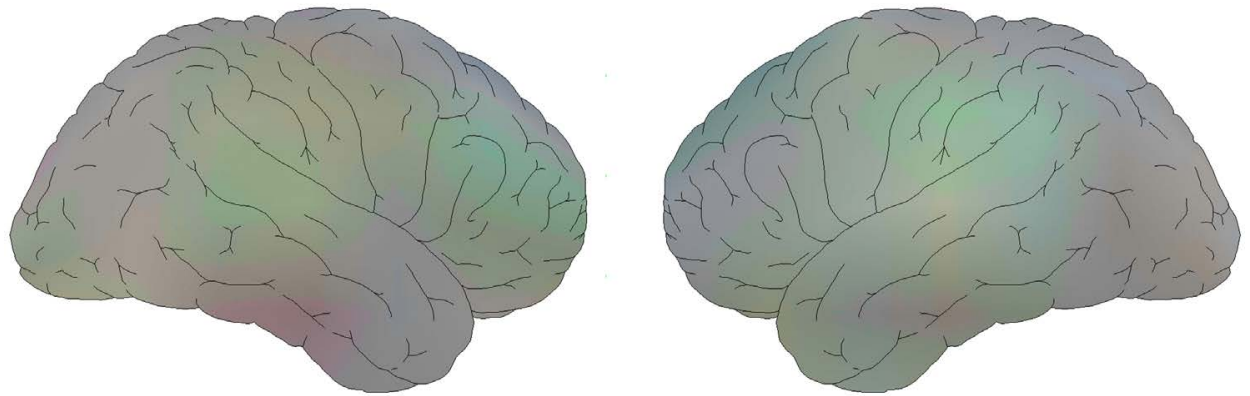

Figure 11. Spectral power differences (recording condition "horror-op") in comparison to the pre-drug period (set to 100\%) $90 \mathrm{~min}$ after intakeof placebo or verum (Calmvalera Hevert tablets) in all brain regions represented by the electrode positions. $\mathrm{C}=$ central, $\mathrm{P}=$ parietal, $\mathrm{O}=$ occipital, $\mathrm{F}=$ frontal, $\mathrm{T}=$ temporal. Even numbers are located in the right hemisphere, uneven numbers in the left one. Frequencies: red $=$ delta, orange $=$ theta, yellow $=$ alpha1, green $=$ alpha2, turquoise $=$ beta 1 and blue $=$ beta2. Statistical significance (wilcoxon-test) between placebo and verum is indicated by stars: ${ }^{*}=\mathrm{p}<0.10{ }^{* *}=\mathrm{p}<0.05 ;^{* * *}=\mathrm{p}<0.01$.

\section{Discussion}

The present investigation contained an entirely new approach with respect to drug studies by using a combination of fast dynamic EEG analysis named "Neurocode-Tracking" in combination with Eye-Tracking [12] now available under the term "Enkephalo Vision". Using this new experimental design electric brain activity was monitored in the presence of several cognitive and emotional challenges. These challenges induced statistically significant frequency changes in the delta, theta and beta range, but rarely in the alpha range in comparison to the relaxed state (recording condition "eyes open") with respect to both brain hemispheres. Beta activity was generally lower in the right hemisphere. 


\section{Picture Comparison}
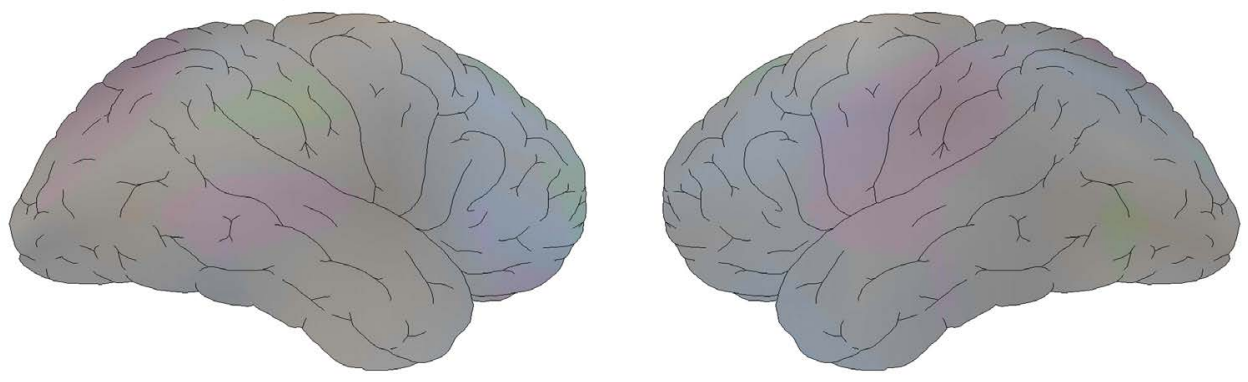

Placebo

$\Delta \Phi C_{z} \quad \Delta \Phi F_{2} \quad \Delta \Phi F_{3} \quad \Delta \Phi C_{3} \quad \Delta \Phi P_{3} \quad \Delta \Phi P_{2} \quad \Delta \Phi P_{4} \quad \Delta \Phi C_{4} \quad \Delta \Phi F_{4} \quad \Delta \Phi F_{7} \quad \Delta \Phi T_{3} \quad \Delta \Phi T_{5} \quad \Delta \Phi O_{1} \quad \Delta \Phi O_{2} \quad \Delta \Phi T_{6} \quad \Delta \Phi T_{4} \quad \Delta \Phi F_{3}$

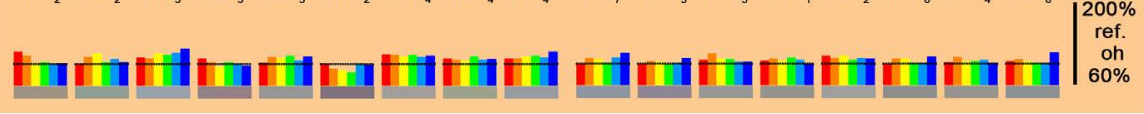

Verum

$\Delta \Phi C_{2} \quad \Delta \Phi F_{2} \quad \Delta \Phi F_{3} \quad \Delta \Phi C_{3} \quad \Delta \Phi P_{3} \quad \Delta \Phi P_{2} \quad \Delta \Phi P_{4} \quad \Delta \Phi C_{4} \quad \Delta \Phi F_{4} \quad \Delta \Phi F_{7} \quad \Delta \Phi T_{3} \quad \Delta \Phi T_{5} \quad \Delta \Phi O_{1} \quad \Delta \Phi O_{2} \quad \Delta \Phi T_{6} \quad \Delta \Phi T_{4} \quad \Delta \Phi F_{8}$

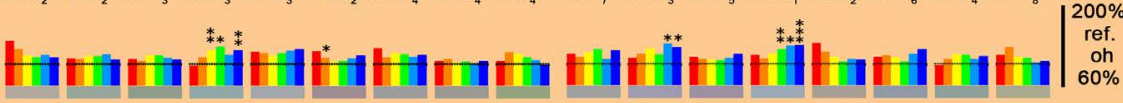
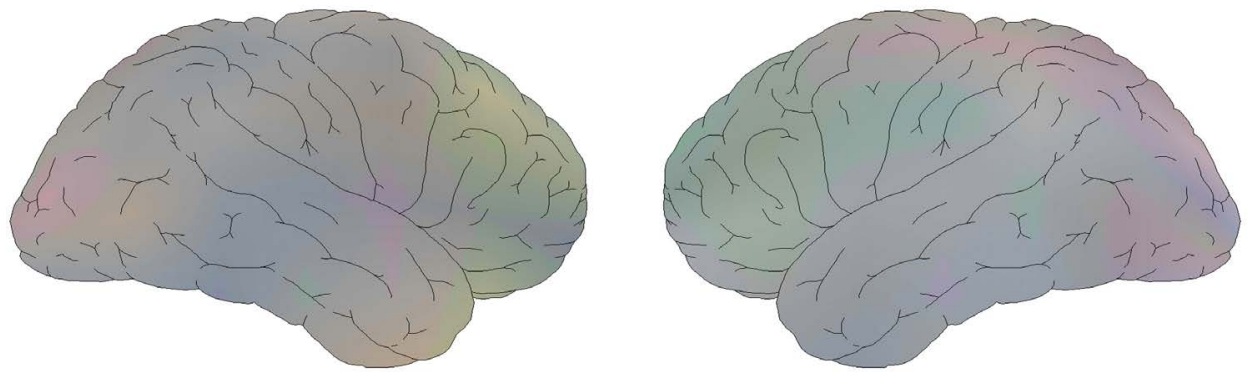

Figure 12. Spectral power differences (recording condition "picture comparison") in comparison to the pre-drug period (set to 100\%) $90 \mathrm{~min}$ after intake of placebo or verum (Calmvalera Hevert tablets) in all brain regions represented by the electrode positions. $\mathrm{C}=$ central, $\mathrm{P}=$ parietal, $\mathrm{O}=$ occipital, $\mathrm{F}=$ frontal, $\mathrm{T}=$ temporal. Even numbers are located in the right hemisphere, uneven numbers in the left one. Frequencies: red = delta, orange $=$ theta, yellow $=$ alpha1, green $=$ alpha2, turquoise $=$ beta 1 and blue $=$ beta2. Statistical significance (wilcoxon-test) between placebo and verum is indicated by stars. ${ }^{*}=\mathrm{p}<0.10$; $^{* *}=\mathrm{p}<0.05$; ${ }^{* *}=\mathrm{p}<0.01$.

Interpretation of spectral EEG changes depends on the recording conditions. For example, general increases of delta activity during relaxation indicate sleepiness and usually are observed during sleep [13]. However, significant focal increases of spectral delta power have been observed during cognitive activity [14] [15]. Our results show statistically significant increases of delta power when compared to the relaxing condition not only during performance of cognitive tasks but also during emotional challenges, thus confirming the results of a recent study using the identical design of "EnkephaloVision" [7]. General increases of theta power have been recognized as indicators of drowsiness and degraded vigilance under the condition of relaxation [16]. On the opposite, focal increases of theta power were reported to occur in frontal brain during increases of cortical activation in conditions of cognitive demands [17]-[19]. Our results are in line with these reports. 

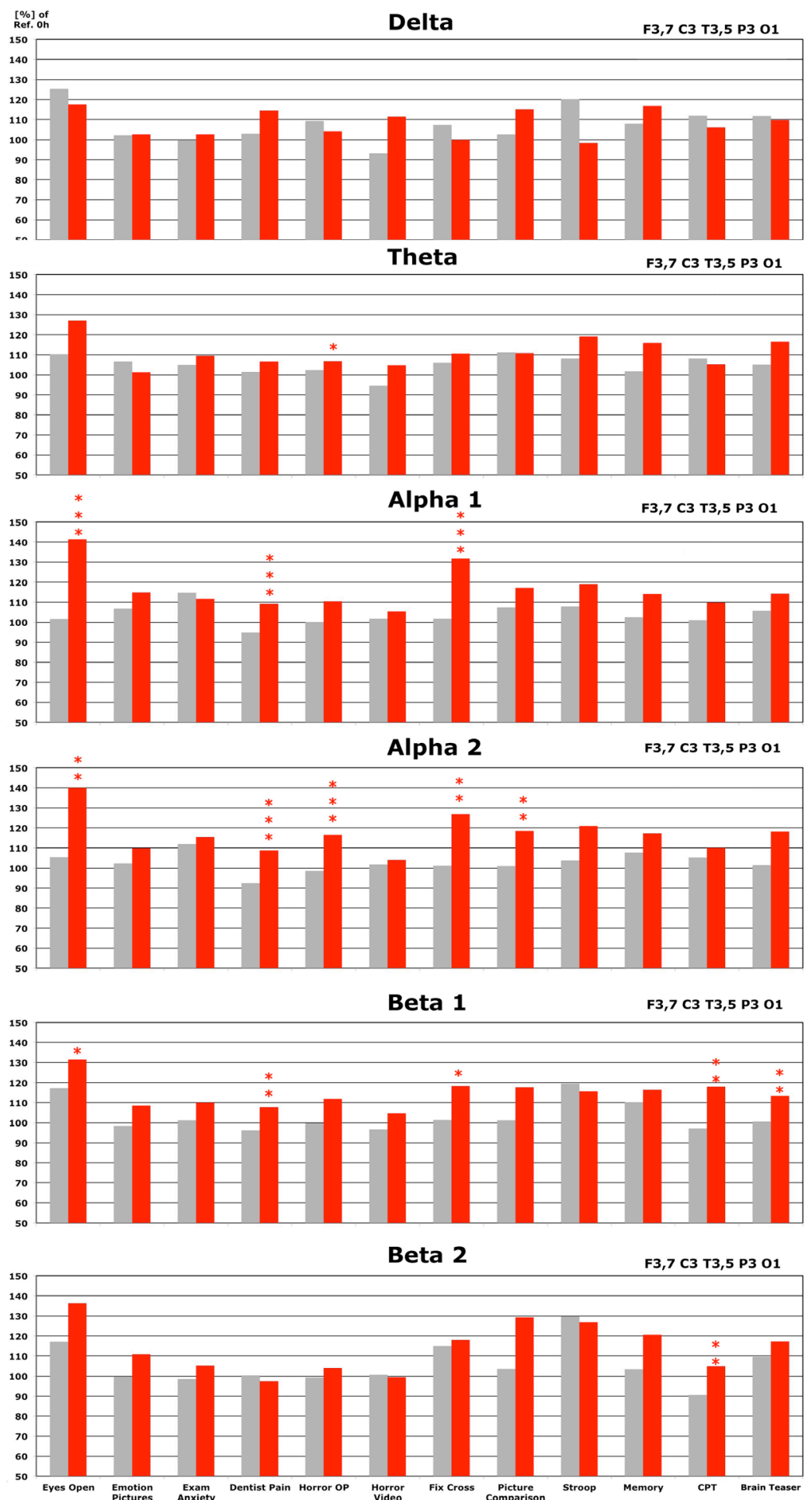

Figure 13. Effect of placebo (grey column) or verum (Calmvalera Hevert tablets $=$ red column) on spectral power during different challenges averaged on selected electrode positions $\left(\mathrm{F}_{3,7} \mathrm{C}_{3} \mathrm{~T}_{3,5} \mathrm{P}_{3} \mathrm{O}_{1}\right)$ representing the left hemisphere. Data are given as $\%$ of baseline $(0 \mathrm{~h}$, ref $=$ reference $)$ before intake. Statistical significance (wilcoxon-test) between placebo and verum is indicated by stars. ${ }^{*}=\mathrm{p}$ $<0.1 ;^{\star *}=\mathrm{p}<0.05 ;^{\star * *}=\mathrm{p}<0.01$. 


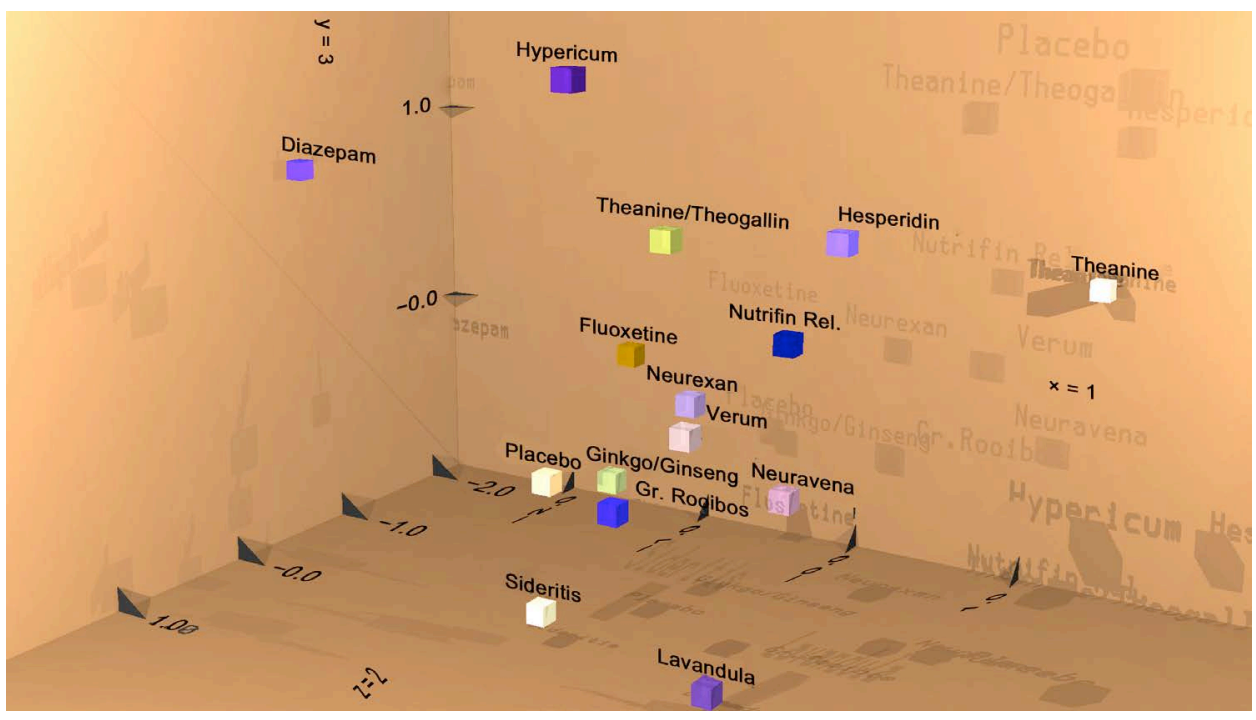

Figure 14. Result of discriminant analysis based on all brain regions and frequencies 90 minutes after intake of Calmvalera Hevert tablets (verum). Results from the first three discriminant functions are depicted with the space coordinates $\mathrm{x}, \mathrm{y}$ and $\mathrm{z}$. Results from the next three discriminant functions are depicted as RGB colour mixture like in TV technology. Difference to baseline is taken for each drug. Diazepam and Fluoxetine are looked at 1 hour after intake, Hypericum 2 hours, all other preparations 3 hours after intake.

Increases of alpha activity have been related to relaxation and calmness in the past as reported in the literature [20]. Large increases of alpha1 activity were observed also in the presence of anti-anxiety drugs i.e. during treatment of schizophrenia [21]. Enhancement of alpha waves has also been observed during meditation [22]. Recent results show, that when alpha power increases, bold connectivity (functional nuclear magnetic resonance imaging (f NMRI)) between the primary visual cortex and occipital brain region decreases and that the negative relation of the visual cortex with the anterior/medial thalamus decreases and the ventral-medial pre-frontal cortex is reduced in strength [23]. Changes of alpha2 spectral activity are associated with mental workload [24] [25].

Comparing now the electric brain patterns before and 90 minutes after intake of six tablets of Calmvalera Hevert there was no influence on spectral delta, theta or beta ac tivity, in general. Calmvalera Hevert did not disturb psychometric performance. However, a statistical significant increase of alpha1 and alpha2 activity was observed in the presence of Calmvalera Hevert during several of the challenges, especially within the left hemisphere. Prevalence of alpha activity is regarded as a safe indicator of higher relaxation and less anxiety as mentioned above. This means that the brain is protected by a disconnection of the electrical circuits between these brain areas. Thus, increases of alpha power induced by Calmvalera Hevert tablets speak in favor of a calming and protective effect and provides objective proof of the action against nervousness and stress Interpretation of such biological surrogate parameters has been supported and reported also by others [26]. Finally, discriminant analysis confirmed statistically the quick and efficient effectiveness of Calmvalera Hevert tablets in comparison to other drugs or. 
Table 8. Mental performance in cognitive tests before and after intake of 6 tablets Calmvalera Hevert (verum) or placebo. No statistical differences were observed between verum and placebo.

\begin{tabular}{|c|c|c|c|}
\hline \multicolumn{4}{|c|}{ Performance of Picture Comparison } \\
\hline & & Placebo & Verum \\
\hline & Mean & 64.79 & 65.63 \\
\hline \multirow[t]{3}{*}{$0 \mathrm{~h}$} & SD & 15.28 & 12.67 \\
\hline & SEM & 4.41 & 3.48 \\
\hline & Mean & 73.96 & 78.13 \\
\hline \multirow[t]{5}{*}{$1.5 \mathrm{~h}$} & SD & 18.24 & 9.42 \\
\hline & SEM & 5.21 & 2.72 \\
\hline & \multicolumn{3}{|c|}{ Performance of Stroop-Test } \\
\hline & & Placebo & Verum \\
\hline & Mean & 100.00 & 100.00 \\
\hline \multirow[t]{3}{*}{$0 \mathrm{~h}$} & SD & 0.00 & 0.00 \\
\hline & SEM & 0.00 & 0.00 \\
\hline & Mean & 100.00 & 100.00 \\
\hline \multirow[t]{5}{*}{$1.5 \mathrm{~h}$} & SD & 0.00 & 0.00 \\
\hline & SEM & 0.00 & 0.00 \\
\hline & \multicolumn{3}{|c|}{ Performance of Memory-Test } \\
\hline & & Placebo & Verum \\
\hline & Mean & 87.83 & 93.75 \\
\hline \multirow[t]{3}{*}{$0 \mathrm{~h}$} & SD & 12.76 & 1.54 \\
\hline & SEM & 3.68 & 4.49 \\
\hline & Mean & 89.58 & 97.92 \\
\hline \multirow[t]{5}{*}{$1.5 \mathrm{~h}$} & SD & 16.71 & 7.22 \\
\hline & SEM & 4.83 & 2.08 \\
\hline & Per & lation $(\mathrm{CP}$ & \\
\hline & & Placebo & Verum \\
\hline & Mean & 52.08 & 27.08 \\
\hline \multirow[t]{3}{*}{$0 \mathrm{~h}$} & SD & 31.00 & 22.51 \\
\hline & SEM & 8.95 & 6.50 \\
\hline & Mean & 62.83 & 37.50 \\
\hline \multirow[t]{5}{*}{$1.5 \mathrm{~h}$} & SD & 33.02 & 34.54 \\
\hline & SEM & 9.53 & 9.97 \\
\hline & & in Teaser & \\
\hline & & Placebo & Verum \\
\hline & Mean & 77.50 & 72.50 \\
\hline \multirow[t]{3}{*}{$0 \mathrm{~h}$} & SD & 9.65 & 16.58 \\
\hline & SEM & 2.79 & 4.79 \\
\hline & Mean & 86.67 & 83.33 \\
\hline \multirow[t]{2}{*}{$1.5 \mathrm{~h}$} & SD & 10.73 & 13.03 \\
\hline & SEM & 3.10 & 3.76 \\
\hline
\end{tabular}


herbal preparations. Projection of the EEG data of Calmvalera Hevert tablets into the close vicinity of Neurexan (a homeopathic drug with proven relaxing properties) and Neuravena (a plant-derived drug marketed for its relaxing property) point to a similar calming action.

A limitation of the study might be seen in the fact that results from the psychometric testing only revealed a positive tendency in the presence of Calmvalera tablets in comparison to placebo. Possibly, statistical significances would have been obtained by including higher numbers of subjects. Due to the low triturations (D2 to D8) of the ingredients of Calmvalera tablets, their efficacy points to the content of highly active molecules in one or more of the single ingredients. Evidence for this hypothesis stems from the preclinical in vivo and in vitro pharmacological characterization of other low homeopathic triturations like for example obtained from Gelsemium and Veratrum [27]. Especially active ingredients from the D3 triturations of Cimicifuga and Passiflora incarnata might be responsible for the observed effects.

\section{Conclusion}

Using the new clinical design "EnkephaloVision", experiments provide evidence, that the homeopathic Calmvalera Hevert tablets are obviously able to change the electric activity of the brain in a statistically significant manner in comparison to placebo. Ninety minutes after intake of 6 tablets (daily dosage) increases of spectral alpha power were observed during relaxation and most of audiovisual challenges in comparison to baseline. Since increases of alpha power are related to higher calmness, efficacy of the homeopathic Calmvalera Hevert tablets is shown by a biological surrogate parameter for relaxation. Comparison to other drugs using discriminant analysis shows, that present data obtained for Calmvalera tablets are projected into the vicinity of other plant-derived calming preparations. Efficacy of Calmvalera tablets point to highly active molecules contained in low triturations (D2 - D8) of this preparation.

\section{Acknowledgements}

Mrs. Ingrid K. Keplinger-Dimpfel is thanked for performance of the logistics of the study and quality control. We greatly appreciate the experimental work as well as the data documentation performed by Mrs. Leonie Schombert.

\section{References}

[1] Dimpfel, W., Pischel, I. and Lehnfeld, R. (2004) Effects of Lozenge Containing Lavender Oil, Extracts from Hops, Lemon Balm and Oat on Electrical Brain Activity of Volunteers. European Journal of Medical Research, 9, 423-431.

[2] Dimpfel, W., Kler, A., Kriesl, E., Lehnfeld, R. and Keplinger-Dimpfel, I.K. (2006) Neurophysiological Characterization of a Functionally Active Drink Containing Extracts of Ginkgo and Ginseng by Source Density Analysis of the Human EEG. Nutritional Neuroscience, 9, 213-224. http://dx.doi.org/10.1080/10284150601043713

[3] Dimpfel, W., Koch, K. and Weiss, G. (2011) Early Effect of NEURAPAS Balance on Current Source Density (CSD) of Human EEG. BMC Psychiatry, 11, 123-138. 
http://dx.doi.org/10.1186/1471-244X-11-123

[4] Dimpfel, W. (2014) Neurophysiological Effects of Rhodiola rosea Extract Containing Capsules. A Double-Blind, Randomised, Placebo-Controlled Study. International Journal of Nutrition and Food Sciences, 3, 157-165.

[5] Dimpfel, W. and Hofmann, H.C. (2014) Neurocode-Tracking Based on Quantitative Fast Dynamic EEG Recording in Combination with Eye-Tracking. World Journal of Neuroscience, 4, 106-119. http://dx.doi.org/10.4236/wjns.2014.42013

[6] Wyczesany, M., Kaiser, J. and Coenen, A.M.L. (2008) Subjective Mood Estimation Co-Varies with Spectral Power EEG Characteristics. Acta Neurobiologiae Experimentalis, 68, 180-192.

[7] Dimpfel, W., Chiegoua Dipah, G.N. and Gericke, N. (2016) Enkephalo Vision: Anatomical Functionality Indicated by Ultrashort Transient Regional EEG Spectral Power Changes during Cognitive and Emotional Challenges. World Journal of Neuroscience, 6, 90-108. http://dx.doi.org/10.4236/wjns.2016.62012

[8] Hodapp, V., Rohrmann, S. and Ringeisen, T. (2011) Prüfungsangstfragebogen PAF-S. Hogrefe Verlag, Göttingen.

[9] HAMD Hamilton Depression Scale (Fragebogen Hamilton Depression Scale 1960 deutsche Version CIPS) (1977) Fremdbeurteilungmit 17 Items.

[10] Hamilton, M. (1959) The Assessment of Anxiety States by Rating. British Journal of Medical Psychology, 32, 50-55. http://dx.doi.org/10.1111/j.2044-8341.1959.tb00467.x

[11] Jasper, H.H. (1958) The Ten-Twenty Electrode System of the International Federation. Electroencephalography and Clinical Neurophysiology, 10, 371-375.

[12] Dimpfel, W. (2015) Drug Discovery and Translational Medicine Based on Neurophysiological Techniques. A Holistic Approach to Saving Animals. Verlag Books on Demand, Norderstedt.

[13] Andreassi, J.L. (2000) Psychophysiology. Human Behavior and Physiological Response. Lawrence Erlbaum Associates, Mahwah, 462 p.

[14] Dolce, G. and Waldeier, H. (1974) Spectral and Multivariate Analysis of EEG Changes during Mental Activity in Man. Electroencephalography and Clinical Neurophysiology, 36, 577-584. http://dx.doi.org/10.1016/0013-4694(74)90224-7

[15] Harmony, T., Fernández, T., Silva, J., Bernal, J., Díaz-Comas, L., Reyes, A., Marosi, E., Rodríguez, M. and Rodríguez, M. (1996) EEG Delta Activity: An Indicator of Attention to Internal Processing during Performance of Mental Tasks. International Journal of Psychophysiology, 24, 161-171. http://dx.doi.org/10.1016/S0167-8760(96)00053-0

[16] Strijkstra, A.M., Beersma, D.G., Drayer, B., Halbesma, N. and Daan, S. (2003) Subjective Sleepiness Correlates Negatively with Global Alpha $(8-12 \mathrm{~Hz})$ and Positively with Central Frontal Theta (4-8 Hz) Frequencies in the Human Resting Awake Electroencephalogram. Neuroscience Letters, 340, 17-20. http://dx.doi.org/10.1016/S0304-3940(03)00033-8

[17] Matsuoka, S. (1990) Theta Rhythms: State of Consciousness. Brain Topography, 3, 203-208. http://dx.doi.org/10.1007/BF01128877

[18] Orekhova, E.V., Stroganova, T.A. and Posikera, I.N. (1999) Theta Synchronization during Sustained Anticipatory Attention in Infants over the Second Half of the First Year of Life. International Journal of Psychophysiology, 32, 151-172. http://dx.doi.org/10.1016/S0167-8760(99)00011-2

[19] Jensen, O. and Tesche, C.D. (2002) Frontal Theta Activity in Humans Increases with Memory Load in a Working Memory Task. European Journal of Neuroscience, 15, 1395-1399. http://dx.doi.org/10.1046/j.1460-9568.2002.01975.x 
[20] Barry, R.J., Clarke, A.R., McCarthy, R., Selikowitz, M., Rushby, J.A. and Ploskova, E. (2004) EEG Differences in Children as a Function of Resting-State Arousal Level. Clinical Neurophysiology, 115, 402-408. http://dx.doi.org/10.1016/s1388-2457(03)00343-2

[21] Schellenberg, R., Milch, W., Schwarz, A., Schober, F. and Dimpfel, W. (1994) Quantitative EEG and BPRS Following Haldol-Deconoate Administration in Schizophrenics. Journal of Clinical Psychopharmacology, 9, 17-24. http://dx.doi.org/10.1097/00004850-199400910-00003

[22] Lomas, T., Ivtzan, I. and Fu, C.H. (2015) A Systematic Review of the Physiology of Mindness on EEG Oscillations. Neuroscience and Biobehavioral Reviews, 57, 401-410. http://dx.doi.org/10.1016/j.neubiorev.2015.09.018

[23] Scheeringa, R., Peterson, K.M., Kleinschmidt, A., Jensen, O. and Bastiaansen, M.C.M. (2012) EEG Alpha Power Modulation of fMRI Resting State Connectivity. Brain Connectivity, 2, 254-264. http://dx.doi.org/10.1089/brain.2012.0088

[24] Crawford, H.J., Clarke, S.W. and Kitner-Triolo, M. (1996) Self-Generated Happy and Sad Emotions in Low and Highly Hypnotizable Persons during Waking and Hypnosis: Laterality and Regional EEG Activity Differences. International Journal of Psychophysiology, 24, 239-266. http://dx.doi.org/10.1016/S0167-8760(96)00067-0

[25] Klimesch, W. (1999) EEG Alpha and Theta Oscillations Reflect Cognitive and Memory Performance: A Review and Analysis. Brain Research Reviews, 29, 169-195. http://dx.doi.org/10.1016/S0165-0173(98)00056-3

[26] Corradini, P.L. and Persinger, M.A. (2015) Replace Psychmetric Inferences with Direct Brain Measurements: LORETA Reflects Traditional Cerebral Loci for Neuropsychological Tests. Neuroscience and Medicine, 6, 107-115. http://dx.doi.org/10.4236/nm.2015.63018

[27] Dimpfel, W. and Biller, A. (2015) Mechanism of Action of Low Dose Preparations from Coffea arabica, Gelsemium and Veratrum Based on in Vivo and in Vitro Neurophysiological Findings. Journal of Behavioral and Brain Science, 5, 368-380. http://dx.doi.org/10.4236/jbbs.2015.59036

\section{Submit or recommend next manuscript to SCIRP and we will provide best service} for you:

Accepting pre-submission inquiries through Email, Facebook, LinkedIn, Twitter, etc. A wide selection of journals (inclusive of 9 subjects, more than 200 journals)

Providing 24-hour high-quality service

User-friendly online submission system

Fair and swift peer-review system

Efficient typesetting and proofreading procedure

Display of the result of downloads and visits, as well as the number of cited articles

Maximum dissemination of your research work

Submit your manuscript at: http://papersubmission.scirp.org/

Or contact jbbs@scirp.org 